Article

\title{
Bordetella holmesii Lipopolysaccharide Hide and Seek Game with Pertussis: Structural Analysis of the O-Specific Polysaccharide and the Core Oligosaccharide of the Type Strain ATCC 51541
}

\author{
Karolina Ucieklak, Sabina Koj and Tomasz Niedziela * \\ Hirszfeld Institute of Immunology and Experimental Therapy, 53-114 Wroclaw, Poland; \\ karolina.ucieklak@hirszfeld.pl (K.U.); sabina.koj@hirszfeld.pl (S.K.) \\ * Correspondence: tomasz.niedziela@iitd.pan.wroc.pl; Tel.: +48-71-337-1172
}

Received: 12 August 2020; Accepted: 28 August 2020; Published: 3 September 2020

check for updates

\begin{abstract}
AbstractWhooping cough is a highly contagious disease caused predominantly by Bordetella pertussis, but it also comprises of a pertussis-like illness caused by $B$. holmesii. The virulence factors of $B$. holmesii and their role in the pathogenesis remain unknown. Lipopolysaccharide is the main surface antigen of all Bordetellae. Data on the structural features of the lipopolysaccharide (LPS) of B. holmesii are scarce. The poly- and oligosaccharide components released by mild acidic hydrolysis of the LPS were separated and investigated by ${ }^{1} \mathrm{H}$ and ${ }^{13} \mathrm{C}$ NMR spectroscopy, mass spectrometry, and chemical methods. The structures of the $\mathrm{O}$-specific polysaccharide and the core oligosaccharide of B. holmesii ATCC 51541 have been identified for the first time. The novel pentasaccharide repeating unit of the $B$. holmesii $\mathrm{O}$-specific polysaccharide has the following structure: $\{\rightarrow 2)-\alpha$-L-Rhap- $(1 \rightarrow 6)-\alpha-\mathrm{D}-\mathrm{Glc} p-(1 \rightarrow 4)-\left[\beta-\mathrm{D}-\mathrm{Glc} p\right.$ NAc- $(1 \rightarrow 3]-\alpha$-D-Gal $p-(1 \rightarrow 3)-\alpha$-D-Glc $p$ NAc- $(1 \rightarrow\}_{\mathrm{n}}$. The SDS-PAGE and serological cross-reactivities of the $B$. holmesii LPS suggested the similarity between the core oligosaccharides of B. holmesii ATCC 51541 and B. pertussis strain 606 . The main oligosaccharide fraction contained a nonasaccharide. The comparative analysis of the NMR spectra of $B$. holmesii core oligosaccharide fraction with this of the B. pertussis strain 606 indicated that the investigated core oligosaccharides were identical.
\end{abstract}

Keywords: whooping cough; pertussis; Bordetella holmesii; Bordetella pertussis; lipopolysaccharide; O-antigen; core; NMR spectroscopy

\section{Introduction}

Bacterial genus Bordetella belongs to the Alcaligenceae family. Bordetellae are Gram-negative, aerobic, and typically small coccobacilli [1]. Extensive molecular analysis of the ribosomal 16S RNA extended the list of known Bordetella species. Currently the Genus comprises sixteen species: B. pertussis, B. parapertussis, B. bronchiseptica, B. holmesii, B. petrii, B. hinzii, B. pseudohinzii, B. trematum, B. avium, B. ansorpii, B. flabillis, B. bronchialis, B. sputigena, B. muralis, B. tumulicola, B. tumbae [2]. The most prominent for the genus Bordetella is Bordetella pertussis-exclusively human pathogen, responsible for whooping cough - a highly contagious disease of respiratory tract, especially dangerous for infants and young children. Some milder form of pertussis may be also caused by Bordetella holmesii, another Bordetella - a human pathogen predominantly isolated from immunocompromised patients $[3,4]$. B. pertussis, B. parapertussis, B. bronchiseptica, that is the classical Bordetellae, are closely related pathogenic bacteria and termed the "Bordetella bronchiseptica cluster" [5]. The initial 16 rRNA analysis of $B$. holmesii indicated that this bacterium was closely related to $B$. pertussis $[1,3]$, but recent genomic data has suggested that there are substantial differences and thus $B$. holmesii does not 
conform to the classical Bordetellae [6]. B. holmesii was initially associated with the infection of the immunosuppressed post-splenectomy patients [3] and only a few years later it was isolated from patients, who manifested pertussis-like symptoms [4]. B. holmesii has also been reported as a causative agent of bacteremia [7], a feature in contrast to B. pertussis. B. holmesii is not a typical mammalian Bordetella-it is closely related to B. pertussis and B. bronchiseptica and shares $\sim 66 \%$ of the genes with these bacteria. However, the genome content has more features resembling these of B. avium and B. petrii. Its evolutionary history can be traced back to avian Bordetellae [8]. Analysis of the clinical isolates of $B$. holmesii indicates that 400 genes are unique for this bacterium and were not found among other Bordetellae. Interestingly, each strain bears between 24 and 114 distinctive genes, and one of those genes was also detected in the E. coli genome. It suggests a susceptibility of $B$. holmesii to a horizontal gene transfer that could explain the acquisition of pertussis-like properties from B. pertussis via such transfer [9]. A limited genetic variability among different strains $B$. holmesii might indicate a fairly recent adaptation to human hosts [6]. The relation between B. pertussis and B. holmesii infections remains unknown, but cases of the co-infection have been reported recently [10-12]. Although the infection rate with $B$. holmesii is low, ranging initially from $<1 \%$ of the diagnosed cases in the US and Canada [11], up to 20\% in France [13] and 29\% in Ohio, USA of patients tested for pertussis [12]. All these data confirmed that $B$. holmesii infects adolescents and adults, however lack of specific diagnostic tools capable of detecting and differentiating Bordetellae, may lead to underestimation of the actual infection rates. It is vital to distinguish B. pertussis and B. holmesii infections efficiently as failing to do so may substantially underrate the efficiency of anti-pertussis vaccination. All Bordetellae have lipopolysaccharides as the most abundant surface antigen and an integral component of the outer membrane of the cell envelope. The structure of lipopolysaccharides (LPS) among Bordetellae conforms to an overall scheme of this amphiphilic molecule composed of lipid A, core oligosaccharide, and O-specific polysaccharide, but differs structurally between species and strains. To further complicate the analysis of the structural features of these LPS some additional oligosaccharide linkers between the core and the O-PS have been identified in B. bronchiseptica and B. parapertussis [14]. All these segments are vital for the physical properties of LPS and the host-pathogen interactions. B. holmesii is a Gram-negative, rod-shaped, slowly-growing bacterium. Since the first report on B. holmesii there were attempts to identify interrelation of this bacterium with B. pertussis, regarding the main virulence factors and antigens. As demonstrated by Zhang et al. neither DTwP nor DTaP pertussis vaccines provide cross-protection against $B$. holmesii [15]. This observation and the genome data indicate that B. holmesii shares some features with other Bordetellae, yet also differs substantially. B. holmesii does not produce the main protein antigens typical for B. pertussis and implicated in the pathogenesis of whooping-cough such as pertussis-toxin, filamentous hemagglutinin, pertactin, adenylate cyclase toxin and fimbrial proteins $[8,15]$. Among the virulence factors of B. bronchiseptica and B. pertussis is LPS [16]. The virulence factors of $B$. holmesii and their role in the pathogenesis remain unknown. However, data on the structural features of the LPS of B. holmesii are scarce. To date, only the structural analysis on the B. holmesii lipid A was published [16]. Thus, for the first time, we describe the structural details of B. holmesii strain ATCC 51541 O-specific polysaccharide and core oligosaccharide segments of LPS and confront them with these typical LPS of the "B. bronchiseptica cluster."

\section{Results}

\subsection{Isolation of Lipopolysaccharides and O-Specific Polysaccharides}

B. holmesii ATCC 51541 and three classical Bordetella species (B. pertussis strains 186 and 606, B. parapertussis strain 529 and B. bronchiseptica strains 530 and 1943) were cultured on the standard Stainer-Scholte (SS) medium. The structure of LPS from bacteria belonging to the "B. bronchiseptica cluster" are well described in the literature [14,17-20], therefore B. pertussis, B. parapertussis, and B. bronchiseptica strains were used as controls in electrophoretic and serological analysis. The growth of $B$. holmesii on the standard SS medium was weak, with very low efficiency, therefore the 
composition of the medium was modified. Recently published research has shown that the addition of riboflavin $(10 \mu \mathrm{g} / \mathrm{mL})$ in case of low B. pertussis density stimulated its growth [21], and likewise, we also observed a better growth of B. holmesii. When compared to the standard SS medium the yield of $B$. holmesii growth on SS medium with riboflavin under the same conditions was doubled (In $250 \mathrm{~mL}$ of medium an increase from $0.1 \mathrm{~g}$ to $0.2 \mathrm{~g}$ of dried bacterial mass was observed).

The LPS of Bordetella species were extracted from dried bacterial mass by the modified hot phenol/water method [22] and purified by ultracentrifugation [23]. The SDS-PAGE analysis of the LPS preparation of different Bordetella species showed the smooth-type LPS of B. holmesii ATCC 51541 and B. parapertussis 529. The rough-type LOS were detected for B. pertussis strains 186 and 606 as well as for B. bronchiseptica strains 530 and 1943 (Figure 1A). The electrophoretic separation of complete lipooligosaccharide (LOS) of B. pertussis yields two bands described as the "A-band" (slow-migrating) and the "B-band" (fast-migrating). The A-band is a complete LOS structure consisting of lipid A, core oligosaccharide, and the distal trisaccharide [ $\alpha$-D-GlcpNAc- $(1 \rightarrow 4)$ $\beta$-D-Man $p 2 N A c 3 N A c A-(1 \rightarrow 3)-\beta-\mathrm{L}-F u c p 2 N A c 4 N M e-(1 \rightarrow]$. B-band is an incomplete LOS that lacks the terminal trisaccharide. The intact oligosaccharide molecule is a dodecasaccharide, and OS that lacks distal trisaccharide is a nonasaccharide. In the SDS-PAGE of B. pertussis 186 LOS both bands are observed. In the SDS-PAGE of LOS of B. pertussis 606 only B-band is present, which confirms that B. pertussis 606 is a rough strain, producing LOS that lacks the distal trisaccharide. B. holmesii ATCC 51541 showed a smooth-type LPS in the SDS-PAGE analysis. We observed a band in the region of lipid A linked to the core and a set of bands in the O-antigen region. In the immunoblotting analysis, the fast migrating core-lipid A band of $B$. holmesii LPS cross-reacted with rabbit sera containing antibodies directed against complete bacterial cells of a mixture of $B$. pertussis strains 186/576/606/629 (Figure 1C) as well as with rabbit sera containing polyclonal antibodies directed against B. pertussis 186 OS-PT glycoconjugate (Figure 1B). Electrophoretic and serological analyses have indicated that the OS structure of B. holmesii core may be similar to the structure of B. pertussis 606 OS.

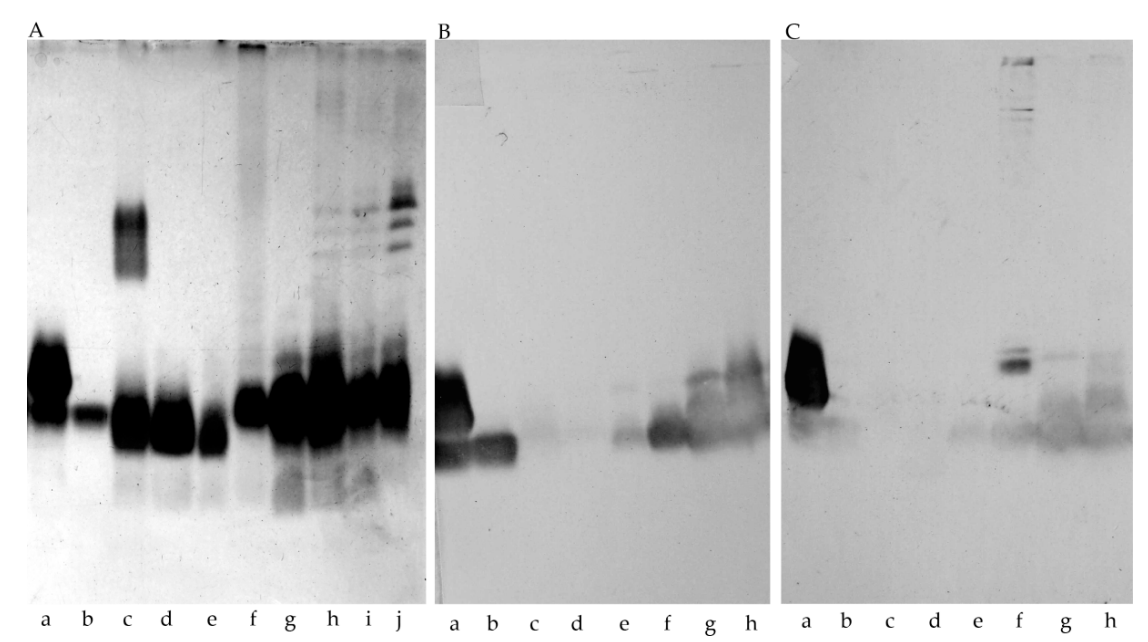

Figure 1. Electrophoretic profiles (A) of the LPS from (a) B. pertussis 186, (b) Bordetella pertussis 606, (c) B. parapertussis 529, (d) B. bronchiseptica 1943, (e) B. bronchiseptica 530 and different preparation of LPS B. holmesii ATCC 51541 (f) Bhol_prep1, (g) Bhol_prep2 and (h) water phase, (i) interphase, (j) phenol phase Bhol_prep3, Immunoblottings with rabbit polyclonal sera: anti-OS-PT (B), anti- complete bacterial cells of a mixture $B$. pertussis (C).

The heteropolysaccharide components of the LPS were released by mild acid hydrolysis and isolated by gel filtration on HiLoad 16/600 Superdex 30 prep grade column in $0.05 \mathrm{M}$ acetic acid (Figure 2). All fractions were analyzed by matrix-assisted laser desorption ionization time-of-flight (MALDI-TOF) mass spectrometry and NMR spectroscopy. The fraction with the shortest retention time (Rt 40-48 min) was identified as O-specific polysaccharide (O-PS I, yield 8.3\%) with the highest degree 
of polymerization. The largest fraction with the longest retention time (OS VIII, yield 23.3\%) was recognized as the core OS. The core oligosaccharides were compared with the known Bordetella cores. The comparative OS analyses were performed with fraction OS VIII (Rt 110-130 min). Fractions O-PS II and O-PS III were identified as the shorter O-specific polysaccharide and fractions OS- IV-OS-VII contained complex mixtures of O-PS and OS components.

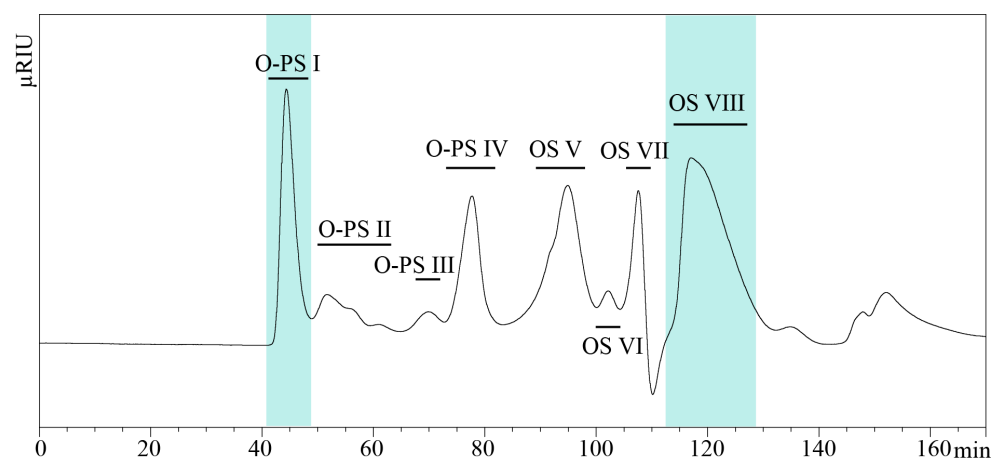

Figure 2. Separation of the O-PS and OS components of B. holmesii ATCC 51541 LPS hydrolyzate by gel-filtration chromatography on the Superdex $30 \mathrm{pg}$, with RI detector.

\subsection{NMR Spectroscopy and Chemical Analysis of the O-PS I}

The ${ }^{1} \mathrm{H}$ NMR spectrum of the isolated O-PSI indicated five anomeric signals, two acetyl resonances, and a methyl group. As the ${ }^{1} \mathrm{H}$ NMR spectrum was complex, the spin systems were identified and assigned by several two-dimensional experiments, including ${ }^{1} \mathrm{H},{ }^{1} \mathrm{H}$ COSY $;{ }^{1} \mathrm{H},{ }^{1} \mathrm{H}$ TOCSY; ${ }^{1} \mathrm{H},{ }^{13} \mathrm{C}$ HSQC-DEPT; ${ }^{1} \mathrm{H},{ }^{13} \mathrm{C} \mathrm{HMBC} ;{ }^{1} \mathrm{H},{ }^{1} \mathrm{H}$ NOESY, and ${ }^{1} \mathrm{H},{ }^{13} \mathrm{C}$ HSQC-TOCSY (Table 1 ). In ${ }^{1} \mathrm{H},{ }^{13} \mathrm{C}$ HSQC-DEPT spectrum (Figure 3) five sugar residues were identified based on the number of anomeric proton and carbon signals. The sugar residues are denoted with the uppercase letters through the manuscript.

Table 1. ${ }^{1} \mathrm{H}$ and ${ }^{13} \mathrm{C}$ NMR chemical shifts of the O-PS of B. holmesii strain ATCC $51541^{\mathrm{a}}$.

\begin{tabular}{|c|c|c|c|c|c|c|}
\hline \multirow{3}{*}{ Residue } & \multicolumn{6}{|c|}{ Chemical Shifts (ppm) } \\
\hline & $\mathrm{H}-1$ & $\mathrm{H}-2$ & H-3 & $\mathrm{H}-4$ & H-5 & H-6, H-6' \\
\hline & $\mathrm{C}-1$ & $\mathrm{C}-2$ & $\mathrm{C}-3$ & $\mathrm{C}-4$ & $\mathrm{C}-5$ & C-6 \\
\hline \multirow{2}{*}{$\mathbf{A} \rightarrow 3,4)-\alpha-\mathrm{D}-\mathrm{Gal} p-(1 \rightarrow$} & 5.51 & 3.93 & 3.80 & 4.28 & 3.98 & $3.82,3.82$ \\
\hline & 99.7 & 68.7 & 79.6 & 77.1 & 72.5 & 60.7 \\
\hline \multirow{2}{*}{$\mathbf{B} \rightarrow 3)-\alpha-\mathrm{D}-\mathrm{Glc} p \mathrm{NAc}-(1 \rightarrow$} & 5.03 & 4.11 & 4.01 & 3.82 & 4.09 & $3.78,3.78$ \\
\hline & 96.8 & 52.7 & 76.8 & 71.2 & 72.6 & 60.7 \\
\hline \multirow{2}{*}{$C \rightarrow 2)-\alpha-L-R h a p-(1 \rightarrow$} & 4.89 & 4.04 & 3.95 & 3.51 & 3.79 & 1.34 \\
\hline & 99.0 & 76.3 & 70.1 & 72.7 & 71.2 & 17.9 \\
\hline \multirow{2}{*}{$C^{\prime} \alpha-\mathrm{L}-$ Rha $p-\left(1 \rightarrow^{\mathrm{b}}\right.$} & $4.89^{c}$ & 4.02 & 3.81 & 3.44 & 3.78 & 1.31 \\
\hline & 99.0 & 70.8 & 69.8 & 73.0 & 69.8 & 17.8 \\
\hline \multirow{2}{*}{$\mathbf{D} \rightarrow 6)-\alpha-\mathrm{D}-\mathrm{Glc} p-(1 \rightarrow$} & 4.92 & 3.51 & 3.72 & 3.57 & 4.34 & $3.93,3.97$ \\
\hline & 100.0 & 72.7 & 73.5 & 69.7 & 71.1 & 67.4 \\
\hline \multirow{2}{*}{ E $\beta$-D-Glc $p$ NAc- $(1 \rightarrow$} & 4.59 & 3.64 & 3.56 & 3.43 & 3.43 & $3.74,3.82$ \\
\hline & 104.8 & 56.5 & 74.9 & 71.0 & 76.5 & 61.5 \\
\hline
\end{tabular}

${ }^{\text {a }}$ Spectra were obtained for ${ }^{2} \mathrm{H}_{2} \mathrm{O}$ solutions at $25^{\circ} \mathrm{C}$. Acetone $\left(\delta_{\mathrm{H}} / \delta_{\mathrm{C}} 2.225 / 31.05 \mathrm{ppm}\right)$ was used as an internal reference; ${ }^{b}$ the non-reducing terminal variant of residue $C .{ }^{c} \delta_{\mathrm{H} 1} / \delta_{\mathrm{C} 1}$ signals of the residues $\mathrm{C}$ and $\mathrm{C}^{\prime}$ were not resolved. 


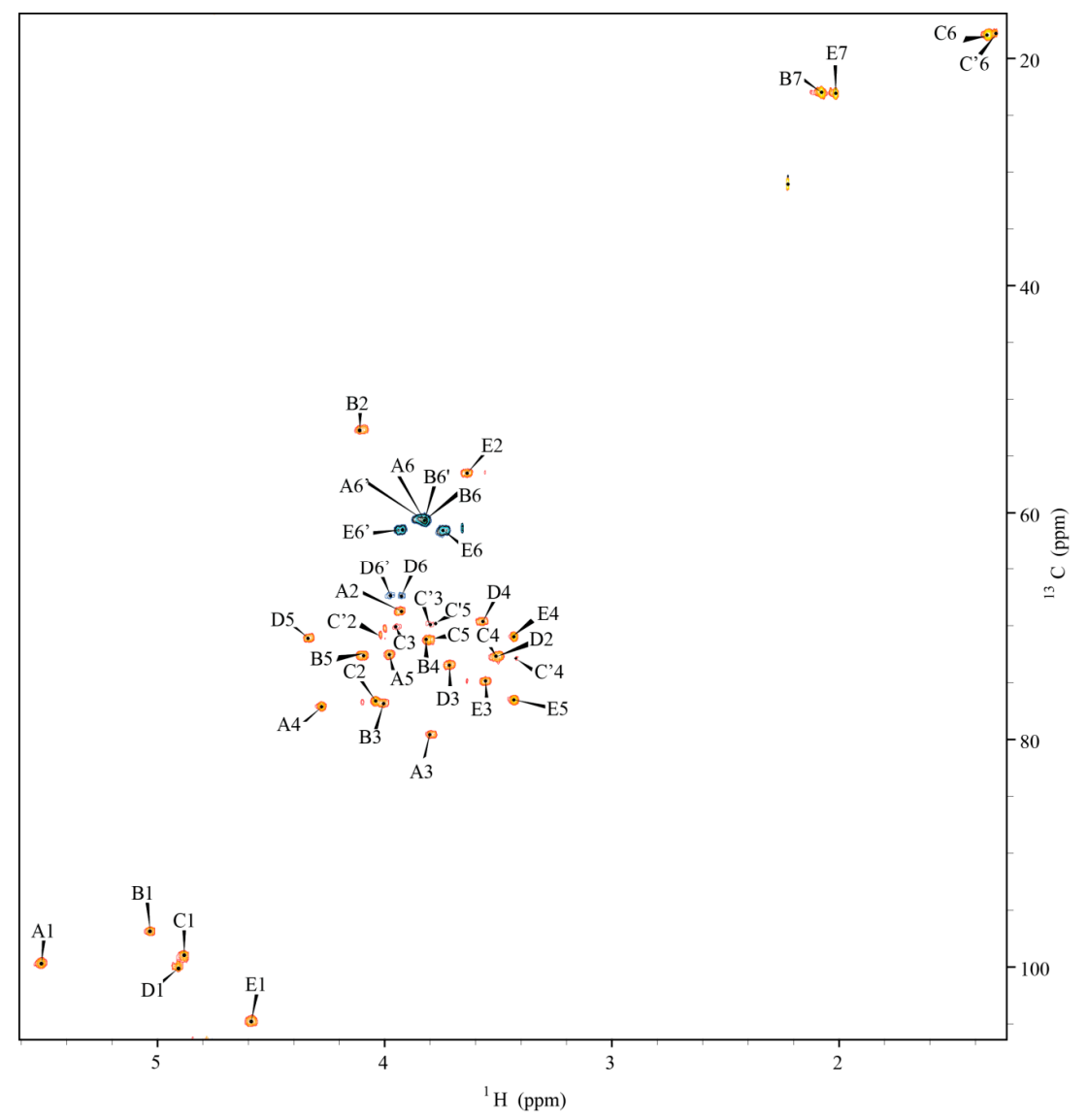

Figure 3. ${ }^{1} \mathrm{H},{ }^{13} \mathrm{C}$ HSQC-DEPT spectrum of the O-PS I of B. holmesii ATCC 51541. The capital letters refer to carbohydrate residues as shown on the structure, and the numbers refer to protons in respective residues.

Residue $\mathbf{A}\left(\delta_{\mathrm{H} 1} / \delta_{\mathrm{C} 1} 5.51 / 99.7\right)$ was identified as the 3,4-disubstituted $\alpha$-D-Galp $[\rightarrow 3,4)-\alpha-\mathrm{D}-\mathrm{Gal} p$ $(1 \rightarrow]$ based on the large coupling between the vicinal protons $\mathrm{H}-2$ and $\mathrm{H}-3$ and the low values of coupling constant between $\mathrm{H}-3, \mathrm{H}-4$, and $\mathrm{H}-5$, as well as the relatively high value of the chemical shifts of the C-3 $\left(\delta_{C} 79.6 \mathrm{ppm}\right)$ and C-4 $\left(\delta_{C} 77.1 \mathrm{ppm}\right)$ signals. Residue $\mathbf{B}\left(\delta_{\mathrm{H} 1} / \delta_{\mathrm{C} 1} 5.03 / 96.8\right)$ was characterized as the 3-substituted $\alpha$-D-Glc $p$ NAc $[\rightarrow 3)-\alpha$-D-Glc $p$ NAc- $(1 \rightarrow]$ based on the large couplings among H-2, H-3, H-4, H-5, H-6 protons in the spin system, and the high chemical shift value of the $\mathrm{C}-3\left(\delta_{\mathrm{C}} 76.8 \mathrm{ppm}\right)$ carbon signal. The chemical shift of the $\mathrm{C}-2$ signal $\left(\delta_{\mathrm{C}} 52.7 \mathrm{ppm}\right)$ was characteristic of the carbon atom with the amine substitution. Residue $\mathrm{C}\left(\delta_{\mathrm{H} 1} / \delta_{\mathrm{C} 1} 4.89 / 99.0\right)$ was assigned as the 2-substituted $\alpha$-L-Rhap $[\rightarrow 2)-\alpha$-L-Rhap-(1 $\rightarrow]$ based on the small couplings of vicinal protons $\mathrm{H}-1, \mathrm{H}-2$ and $\mathrm{H}-3$ and the high values of couplings between $\mathrm{H}-3, \mathrm{H}-4$ and $\mathrm{H}-5$, the high chemical shift value of the $\mathrm{C}-2\left(\delta_{\mathrm{C}} 76.3 \mathrm{ppm}\right)$ carbon signal and based on the characteristic signal of the exocyclic $\mathrm{CH}_{3}$ group $\left(\delta_{\mathrm{C}} 17.9, \delta_{\mathrm{H}} 1.34 \mathrm{ppm}\right)$. The presence of the $\mathrm{C}^{\prime}$ variant with chemical shifts similar to residue $\mathrm{C}$ was attributed to a non-reducing terminal variant of residue $\mathrm{C}$, defining the biological repeating unit of the $O$-specific polysaccharide. Residue $\mathbf{D}\left(\delta_{\mathrm{H} 1} / \delta_{\mathrm{C} 1} 4.92 / 100.0\right)$ was characterized as the 6-substituted $\alpha$-D-Glc $p[\rightarrow 6)-\alpha$-D-Glc $p-(1 \rightarrow]$ based on the large couplings between $\mathrm{H}-2, \mathrm{H}-3, \mathrm{H}-4$, and $\mathrm{H}-5$ protons in the spin system and also the high value of the C-6 $\left(\delta_{C} 67.4 \mathrm{ppm}\right)$ carbon chemical shift. Residue $\mathbf{E}$ $\left(\delta_{\mathrm{H} 1} / \delta_{\mathrm{C} 1} 4.59 / 104.8\right)$ was identified as the terminal $\beta$-D-Glc $p$ NAc $[\beta-\mathrm{D}-\mathrm{Glc} p \mathrm{NAc}-(1 \rightarrow]$ based on the large couplings between all protons in the spin system. The low chemical shift of the $C-2$ signal $\left(\delta_{C} 56.5 \mathrm{ppm}\right)$ indicated the amine substitution. Substitutions with the $\mathrm{N}$-acetyl groups were identified in an ${ }^{1} \mathrm{H},{ }^{13} \mathrm{C}$ $\mathrm{HMBC}$ experiment using the correlation of the carbonyl carbon of the acetyl groups at $\delta_{C} 175.1 \mathrm{ppm}$ and $\delta_{\mathrm{C}} 175.4 \mathrm{ppm}$ to $\mathrm{H}-2$ protons of residues $\mathbf{B}\left(\delta_{\mathrm{H}} 4.11 \mathrm{ppm}\right)$ and $\mathbf{E}\left(\delta_{\mathrm{H}} 3.64 \mathrm{ppm}\right)$, respectively. The $\mathrm{J}_{\mathrm{C} 1, \mathrm{H} 1}$ coupling values obtained from the non-decoupled HSQC experiment confirmed the $\alpha$-pyranosyl 
configuration of residues A $(179 \mathrm{~Hz}), \mathbf{B}(172 \mathrm{~Hz}), \mathbf{C}(172 \mathrm{~Hz})$ and $\mathbf{D}(172 \mathrm{~Hz})$ and the $\beta$-pyranosyl configuration for residue $\mathbf{E}(164 \mathrm{~Hz})$. The sequence of monosaccharides in the O-PS I was determined using inter-residue correlations observed as cross-peaks between the transglycosidic protons in the ${ }^{1} \mathrm{H},{ }_{1}^{1} \mathrm{H}$ NOESY experiment, and between the anomeric protons and carbons at the linkage position in the ${ }^{1} \mathrm{H},{ }^{13} \mathrm{C}$ HMBC spectrum (Table 2, Figure 4).

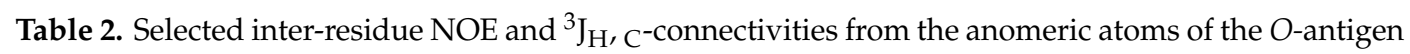
repeating unit of PS B. holmesii ATCC 51541.

\begin{tabular}{|c|c|c|c|c|}
\hline \multirow{2}{*}{ Residue } & \multirow{2}{*}{$\begin{array}{c}\begin{array}{c}\text { Atom } \\
\text { H-1/C-1 }\end{array} \\
\text { (ppm) }\end{array}$} & \multicolumn{2}{|c|}{ Connectivities to } & \multirow{2}{*}{$\begin{array}{l}\text { Inter-Residue } \\
\text { Atom/Residue }\end{array}$} \\
\hline & & $\delta_{C}$ & $\delta_{H}$ & \\
\hline $\mathbf{A} \rightarrow 3,4)-\alpha-\mathrm{D}-\mathrm{Gal} p-(1 \rightarrow$ & $5.51 / 99.7$ & 76.8 & 4.01 & C-3, H-3 of B \\
\hline $\mathbf{B} \rightarrow 3)-\alpha-\mathrm{D}-\mathrm{Glc} p$ NAc- $(1 \rightarrow$ & $5.03 / 96.8$ & 76.3 & 4.04 & $\mathrm{C}-2, \mathrm{H}-2$ of $\mathrm{C}$ \\
\hline $\mathrm{C} \rightarrow 2)-\alpha-\mathrm{L}-\mathrm{Rha} p-(1 \rightarrow$ & $4.89 / 99.0$ & 67.4 & $3.93 / 3.97$ & C- $6, \mathrm{H}-6 / 6^{\prime}$ of $\mathrm{D}$ \\
\hline $\mathrm{D} \rightarrow 6)-\alpha-\mathrm{D}-\mathrm{Glc} p-(1 \rightarrow$ & $4.92 / 100.0$ & 77.1 & 4.28 & C- $4, \mathrm{H}-4$ of $\mathrm{A}$ \\
\hline E $\beta$-D-Glc $p$ NAc- $(1 \rightarrow$ & $4.59 / 104.8$ & 79.6 & 3.80 & C-3, H-3 of $\mathbf{A}$ \\
\hline
\end{tabular}
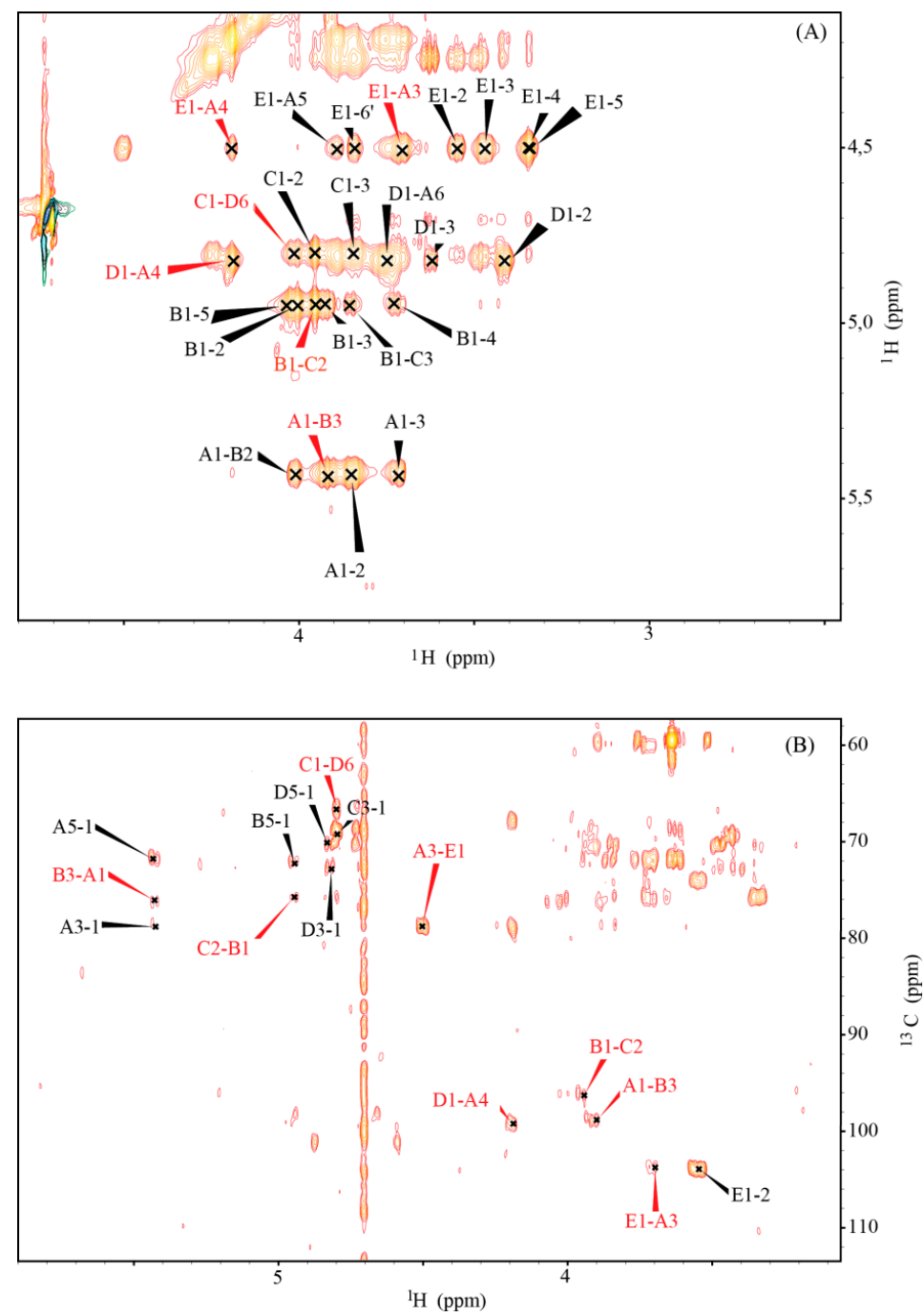

Figure 4. Part of the ${ }^{1} \mathrm{H},{ }^{1} \mathrm{H}$ NOESY spectrum (A) and selected ${ }^{3} \mathrm{~J}_{\mathrm{H}, \mathrm{C}}$ - connectivities in the ${ }^{1} \mathrm{H},{ }^{13} \mathrm{C}$ HMBC (B) spectrum of O-PS I B. holmesii ATCC 51541. Inter-residue cross-peaks are marked red. 
Sugar analysis of the O-PS I confirmed the presence of rhamnose, glucose, galactose, and $\mathrm{N}$-acetylglucosamine. The absolute configuration of the monosaccharide components of PS B. holmesii was confirmed by the method described by York et al. [24]. This method allows us to define the absolute configuration of sugar residues in the PS using only NMR spectroscopy. The O-(S)-2-methyl butyrate (SMB) derivatives of $\mathrm{D}$ - and $\mathrm{L}$ - monosaccharides are diastereomeric and can be differentiated by comparing their chemical shift and coupling patterns. The polysaccharides were hydrolyzed with 2 M TFA and the resulting monosaccharides were converted into (SMB) derivatives, and then their absolute configurations were analyzed by ${ }^{1} \mathrm{H}$ NMR spectroscopy (Figure 5). The samples were dissolved in deuterated acetone (acetone-d6) and all the spectra were calibrated to the internal reference of acetone-d5 ( $\delta 2.05 \mathrm{ppm}$ ). Comparison of ${ }^{1} \mathrm{H}$ NMR profile of the SMB-modified PS hydrolysate of $B$. holmesii ATCC 51541 and the SMB-derivatives of the selected monosaccharides confirmed the presence of D-Glc, D-Gal and L-Rha. The analysis also revealed the presence of an SMB-derivative of D-GlcN instead of the expected SMB-derivative of GlcNAc. This observation can be explained by the release of the $\mathrm{N}$-acetyl group from the GlcNAc during hydrolysis in concentrated acid, and thus required the use of GlcN as an additional standard. The presence of GlcNAc in the native O-PS was supported by NMR and sugar analysis data.

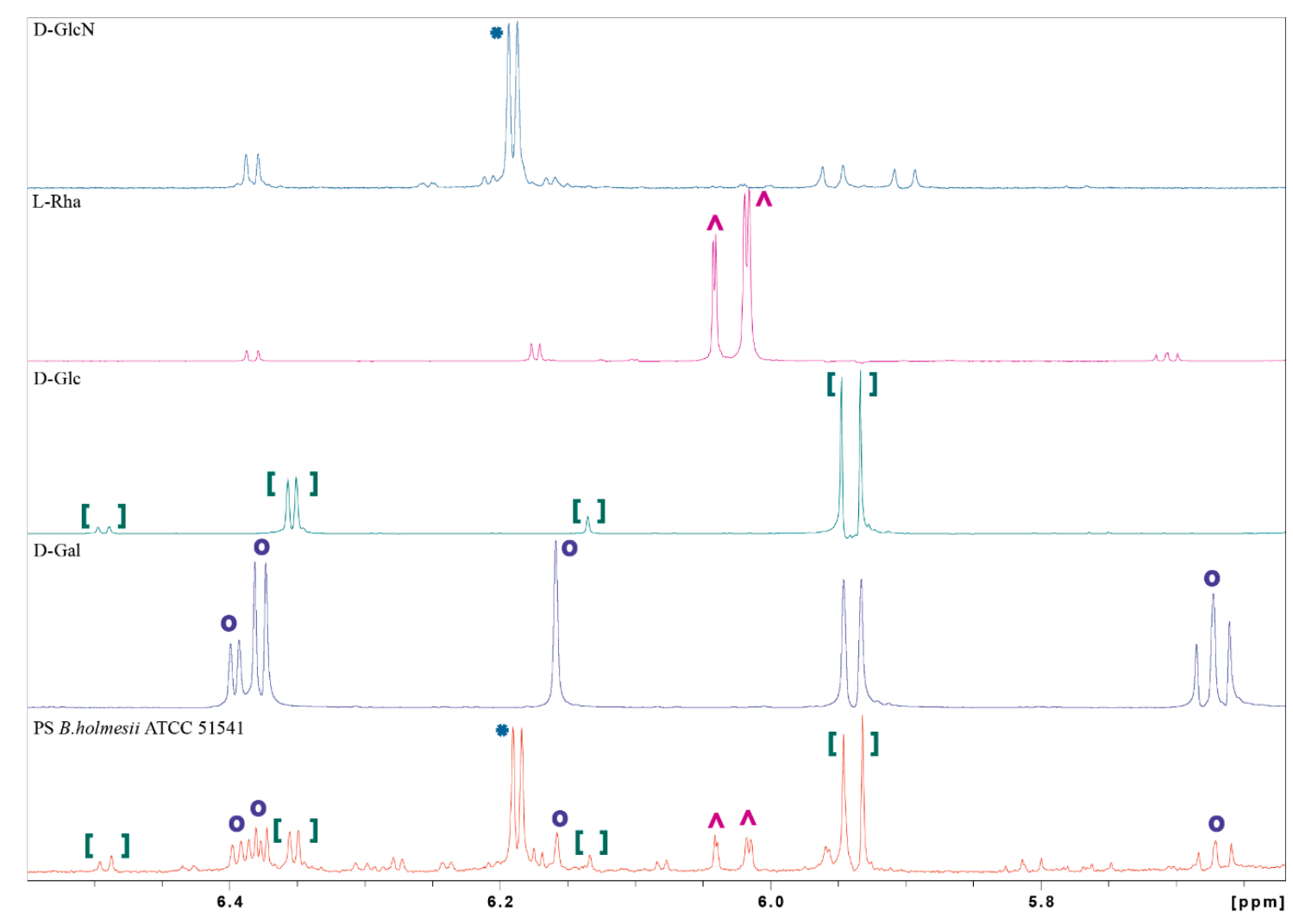

Figure 5. Comparison of NMR spectral profiles in the range of 5.5-6.5 ppm for O-(S)-2-methyl butyrate derivatives of monosaccharide standards and the B. holmesii O-PS hydrolyzate. The signs " $\mathrm{o},{ }^{*}$, , , []" indicate the standard signals identified in the O-PS. The spectra were obtained for acetone-d6 solutions at $25^{\circ} \mathrm{C}$ and calibrated to the internal reference of acetone-d5 ( $\left.\delta 2.05 \mathrm{ppm}\right)$.

\subsection{Structural Analysis of the O-PS I by Mass Spectrometry}

As the attempts to obtain MALDI-TOF spectra of the intact O-PS I failed, the mass of the repeating unit of B. holmesii strain ATCC 51541 has been deduced from the analysis of the partially hydrolyzed O-PS fractions obtained after treatment with $48 \% \mathrm{HF}$ at $-20^{\circ} \mathrm{C}$ for 26 days. The MALDI-TOF mass spectrum (Figure 6), recorded in the positive polarization reflectron mode, after partial hydrolysis of 
PS B. holmesii, contained main ions at $m / z$ 899.25, $\mathrm{m} / \mathrm{z} 1775.40, \mathrm{~m} / \mathrm{z} 2651.53, \mathrm{~m} / \mathrm{z} 3527.63, \mathrm{~m} / \mathrm{z} 4406.56$ and $m / z 5285.37$ with a mass difference of $\sim 876$ Da between the main signals. This value corresponds to the theoretical mass of the subunit devoid of the water molecule. The dominant ion of $m / z 899.25$, was interpreted as the sodium adduct of a single repeating unit devoid of a water molecule $\left[\mathrm{M}+\mathrm{Na}-\mathrm{H}_{2} \mathrm{O}\right]^{+}$. These results confirm the theoretical mass $(876.32 \mathrm{Da})$ of the O-PS repeating unit of B. holmesii.

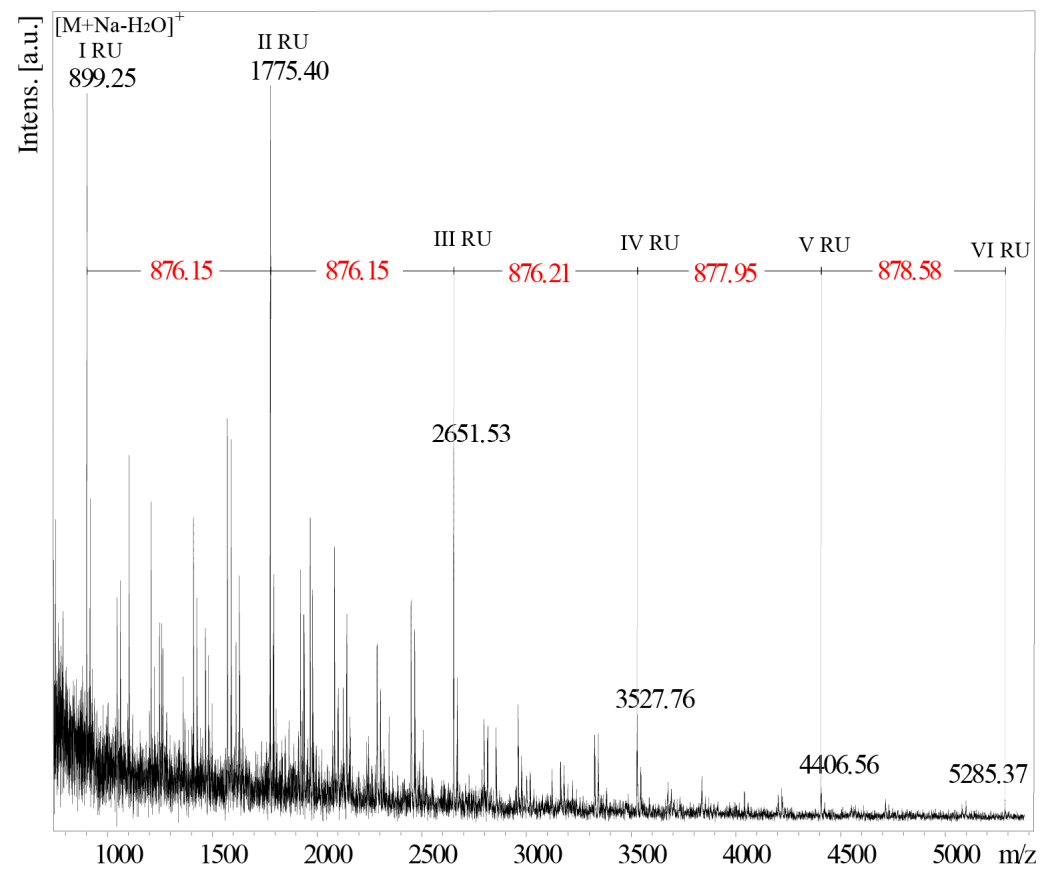

Figure 6. MALDI TOF-MS spectrum of oligosaccharides and trimmed O-PS segments obtained by partial acid hydrolysis of the O-PS I of B. holmesii ATCC 51541 (26th day of the experiment). The spectrum was obtained in the positive reflectron mode with the DHB as a matrix.

The combined NMR and MS data showed that the repeating unit of the O-antigen of $B$. holmesii ATCC 51541 is the $\rightarrow 2)-\alpha$-L-Rhap- $(1 \rightarrow 6)-\alpha-D-G l c p-(1 \rightarrow 4)-[\beta-D-G l c p N A c-(1 \rightarrow 3)]-$ $\alpha$-D-Galp- $(1 \rightarrow 3)-\alpha$-D-GlcpNAc- $(1 \rightarrow$ pentasaccharide with the following structure (Figure 7$)$.

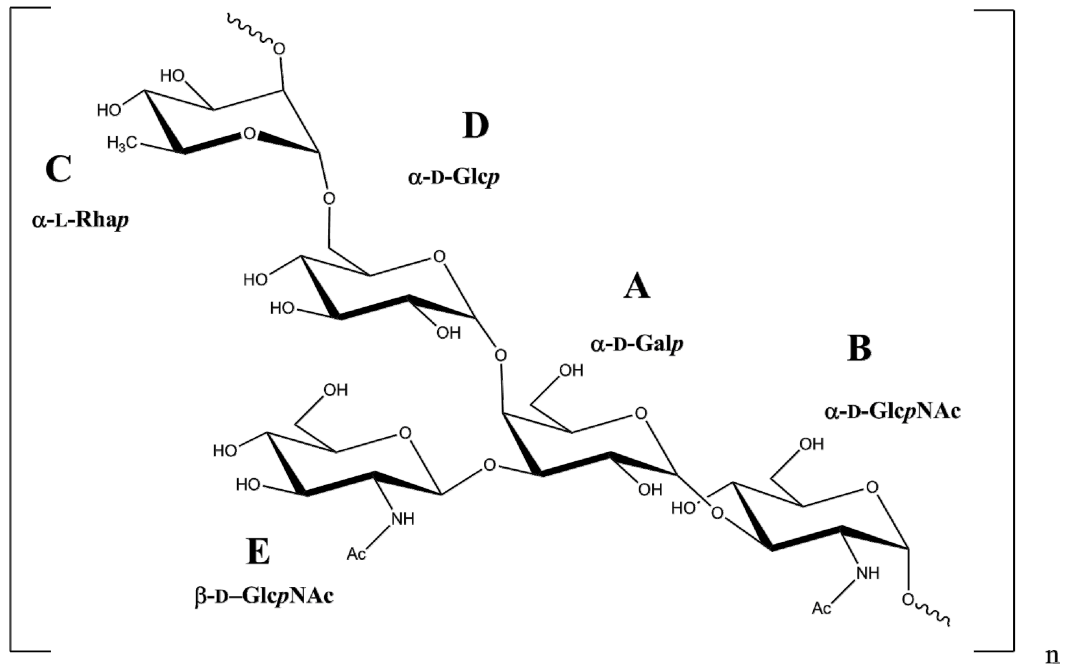

Figure 7. Structure of the O-repeating unit of the O-PS of B. holmesii ATCC 51541. 


\subsection{Structural Analysis of the OS Core}

An initial SDS-PAGE analysis of the intact LPS of B. holmesii and the observed cross-reactivities of the anti-B. pertussis 186 OS-PT antibodies with the fast migrating bands suggested some structural similarity with the core oligosaccharides of $B$. pertussis strains 186 and 606 (Figure 1), thus we compared the ${ }^{1} \mathrm{H}$ NMR profiles of the corresponding oligosaccharides. ${ }^{1} \mathrm{H}$ NMR spectra of the $B$. pertussis strains 186 and 606 OS (Figure 8) provide information on the reporter groups in the ${ }^{1} \mathrm{H}$ NMR spectra of these oligosaccharide structures. As mentioned before, B. pertussis produces two types of LOS. The complete OS molecule is a dodecasaccharide that includes the distal trisaccharide and the incomplete OS molecule is devoid of it. Chemical shift values for B. pertussis 186 have been reported [14,19] and are in line with the data published for the B. pertussis 1414 strain [17]. The B. pertussis 606 strain produces only one type of LOS, comprising lipid A linked to a nonasaccharide (Tables S1 and S2). The nonasaccharide is easily identifiable as it lacks the main reporter groups of the distal trisaccharide of $B$. pertussis LOS-the signals of the N-methyl resonance and the deoxy-group of $\beta$-L-Fucp $2 \mathrm{NAc} 4 \mathrm{NMe}$. We compared ${ }^{1} \mathrm{H}$ NMR spectrum of yet unknown core OS of B. holmesii ATCC 51541 with the OS of B. pertussis strains 186 and 606. Notably, the observed similarity of the B. holmesii ATCC 51541 OS profile in the anomeric region in comparison with the ${ }^{1} \mathrm{H}$ NMR profile of B. pertussis strain 606 OS indicated common structural elements.

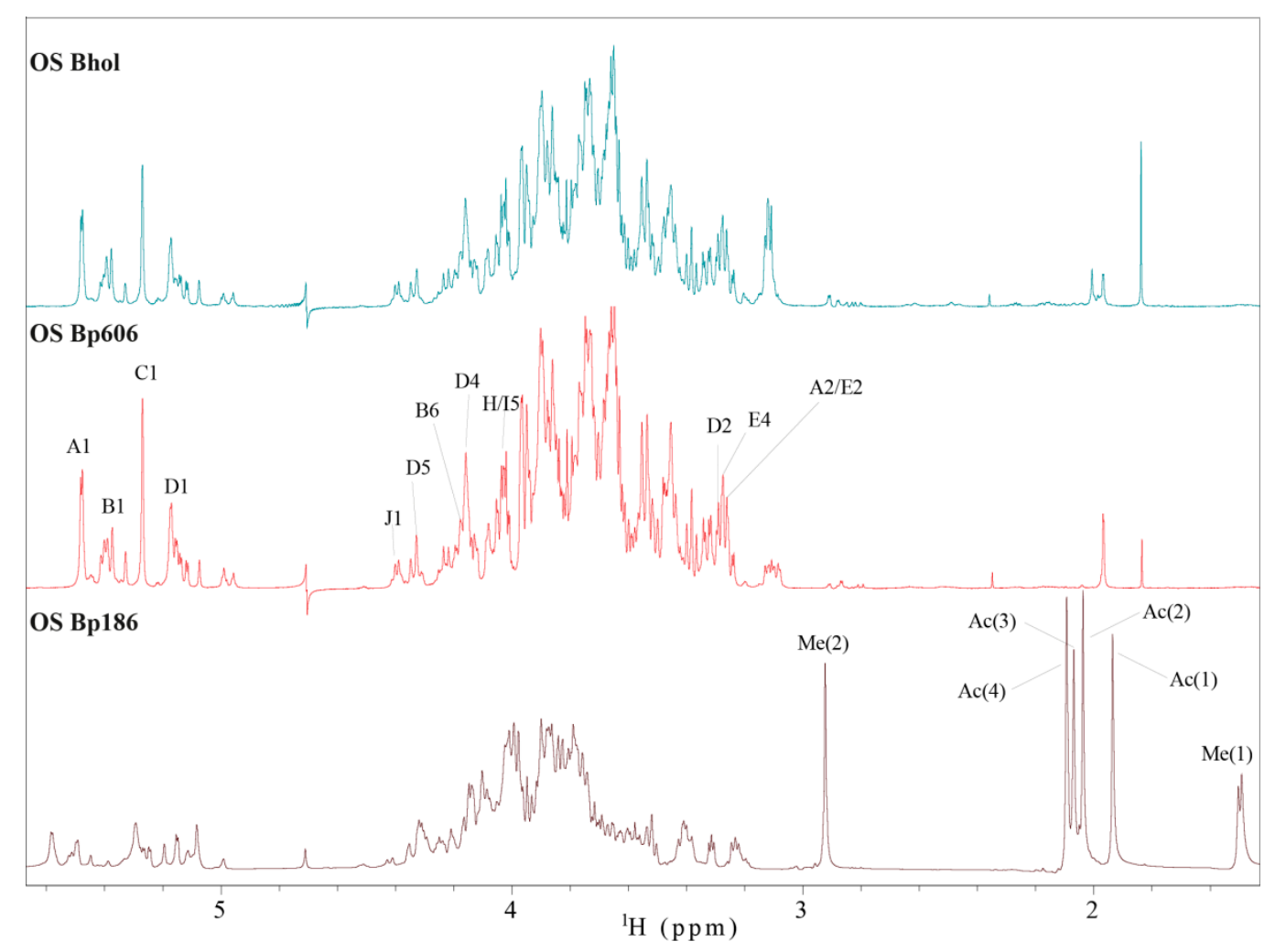

Figure 8. Structure reporter groups in the ${ }^{1} \mathrm{H}$ NMR spectra of the oligosaccharides of $B$. pertussis (strains 186 and 606) and B. holmesii ATCC 51541. The capital letters refer to carbohydrate residues as shown on the structure, and the numbers refer to protons in respective residues. The resonances marked with $\mathrm{Me}(1), \mathrm{N}$-methyl, $\mathrm{Me}(2)$, exocyclic $\mathrm{CH}_{3}$ and $\mathrm{Ac}(4), \mathrm{N}$-acetyl of L-Fucp2NAc4NMe, $A c(1)$ and Ac(3), N-acetyls of Manp2NAc3NAcA and Ac(2), N-acetyl of Glc $p$ NAc indicate the distal $[\alpha$-D-Glc $p$ NAc- $(1 \rightarrow 4)-\beta$-D-Man $p 2 N A c 3 N A c A-(1 \rightarrow 3)-\beta$-L-Fucp $2 N A c 4 N M e-(1 \rightarrow]$ trisaccharide in the structure of B. pertussis 186 LOS.

The MALDI-TOF MS spectrum (Figure 9) recorded for the OS VIII of B. holmesii showed a series of ions with $\mathrm{m} / \mathrm{z} 1632.47, \mathrm{~m} / \mathrm{z} 1654.42, \mathrm{~m} / \mathrm{z} 1676.40, \mathrm{~m} / \mathrm{z} 1698.38$ and $\mathrm{m} / \mathrm{z} 1720.35$. The ion at $\mathrm{m} / \mathrm{z} 1632.47$ 
corresponds to a theoretical monoisotopic mass of nonasaccharide (1649.5 Da) devoid of a water molecule. The difference between successive ions correlates with the multiple sodium adduct. In the gel-filtration chromatography, the Rt (110-130 min) of the main OS fraction of $B$. holmesii core (OS VIII) matches up with the Rt (112-135 min) of the main OS fraction of B. pertussis 606 . These observations were further supported by NMR data.

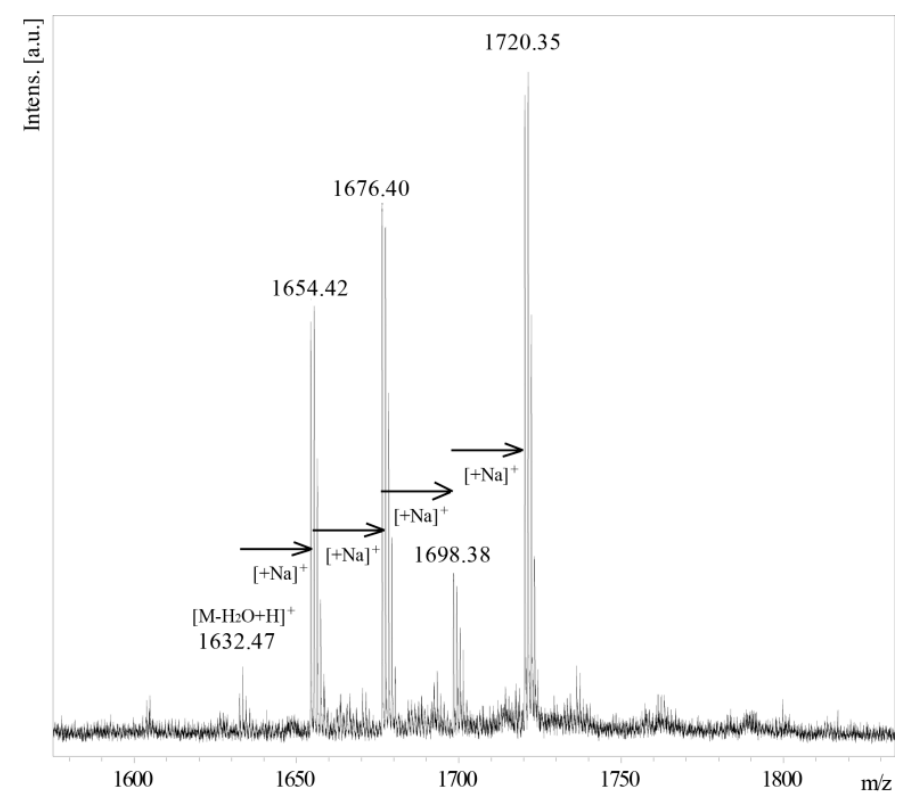

Figure 9. MALDI-TOF MS spectrum of OS VIII B. holmesii ATCC 51541 in positive reflectron mode with DHB as a matrix.

To verify the structural similarities between the core oligosaccharides of $B$. holmesii ATCC 51541 and $B$. pertussis 606, the corresponding spin systems of the both OS were identified and assigned by two dimensional NMR experiments, including ${ }^{1} \mathrm{H},{ }^{1} \mathrm{H}$ COSY; ${ }^{1} \mathrm{H},{ }^{1} \mathrm{H}$ TOCSY; ${ }^{1} \mathrm{H},{ }^{13} \mathrm{C}$ HSQC-DEPT; ${ }^{1} \mathrm{H}$, ${ }^{13} \mathrm{C} \mathrm{HMBC} ;{ }^{1} \mathrm{H},{ }^{1} \mathrm{H}$ NOESY, and ${ }^{1} \mathrm{H},{ }^{13} \mathrm{C}$ HSQC-TOCSY. Here we describe the chemical shift values of all individual sugar residues for the B. holmesii ATCC 51541 (Table 3) and B. pertussis 606 for the first time (Table S1).

Residue A $\left(\delta_{\mathrm{H} 1} / \delta_{\mathrm{C} 1} 5.48 / 97.3 \mathrm{ppm}\right)$ was identified as the 4-substituted $\alpha$-Glc $p \mathrm{~N}[\rightarrow 4)-\alpha$-Glc $p \mathrm{~N}-(1 \rightarrow]$ based on large coupling constants between $\mathrm{H}-2, \mathrm{H}-3, \mathrm{H}-4$, and $\mathrm{H}-5$ in the spin system, as well as the relatively high value of the chemical shift of the $C-4\left(\delta_{C} 74.9 \mathrm{ppm}\right)$ signal. The chemical shift of the C-2 signal $\left(\delta_{C} 54.5 \mathrm{ppm}\right)$ implied substitution with an amine group. Residue $\mathrm{B}\left(\delta_{\mathrm{H}} / \delta_{\mathrm{C}} 5.39 / 99.7 \mathrm{ppm}\right)$ was recognized as the 2,7-disubstituted-L-glycero- $\alpha$-D-manno-Hep $p[\rightarrow 2,7-\mathrm{L}-\alpha-\mathrm{D}-\mathrm{Hep} p-(1 \rightarrow]$ from the ${ }^{1} \mathrm{H}$ and ${ }^{13} \mathrm{C}$ chemical shifts, the small vicinal couplings between $\mathrm{H}-1, \mathrm{H}-2$ and $\mathrm{H}-3$ and the relatively high chemical shifts of the C-2 $\left(\delta_{C} 79.8 \mathrm{ppm}\right)$ and C-7 $\left(\delta_{\mathrm{C}} 70.4 \mathrm{ppm}\right)$ signals. Residue $C\left(\delta_{\mathrm{H} 1} / \delta_{\mathrm{C} 1}\right.$ $5.27 / 101.2 \mathrm{ppm})$ was assigned as the terminal L-glycero- $\alpha$-D-manno-Hep $p$ [L- $\alpha$-D-Hep $p-(1 \rightarrow]$ based on the ${ }^{1} \mathrm{H}$ and ${ }^{13} \mathrm{C}$ chemical shifts and thee small vicinal couplings between $\mathrm{H}-1, \mathrm{H}-2$, and $\mathrm{H}-3$. Residue D $\left(\delta_{\mathrm{H} 1} / \delta_{\mathrm{C} 1} 5.17 / 94.4\right)$ was identified as the terminal $\alpha$-Gal $p$ NA [ $\alpha$-Gal $p$ NA- $(1 \rightarrow]$ based on the large couplings between vicinal protons $\mathrm{H}-1, \mathrm{H}-2$, and $\mathrm{H}-3$ and the small couplings among $\mathrm{H}-3, \mathrm{H}-4$, and H-5. The low chemical shift of the C-2 signal $\left(\delta_{C} 50.5 \mathrm{ppm}\right)$ indicated substitution with an amine group. The characteristic five-proton spin system and the high values of the chemical shifts of $\mathrm{H}-4$ $\left(\delta_{\mathrm{H}} 4.16 \mathrm{ppm}\right), \mathrm{H}-5\left(\delta_{\mathrm{H}} 4.33 \mathrm{ppm}\right)$, and C-5 $\left(\delta_{\mathrm{C}} 175.1 \mathrm{ppm}\right)$ resonances allowed to identify this residue as aminouronic acid. Residue $\mathbf{E}\left(\delta_{\mathrm{H} 1} / \delta_{\mathrm{C} 1} 5.12 / 96.0\right)$ was recognized as the terminal $\alpha-\mathrm{Glc} p \mathrm{~N}$ [ $\alpha-\mathrm{Glc} p \mathrm{~N}-(1 \rightarrow]$ based on the large coupling constants between H-2, H-3, H-4, and H-5 in the spin system and the chemical shift of C-2 signal $\left(\delta_{\mathrm{C} 1} 54.1 \mathrm{ppm}\right)$. Residue $\mathbf{F}\left(\delta_{\mathrm{H} 1} / \delta_{\mathrm{C} 1} 5.07 / 97.8\right)$ was characterized as the 3,4-disubstituted-L-glycero- $\alpha$-D-manno-Hep $p\left[\rightarrow 3,4-\mathrm{L}-\alpha\right.$-D-Hep $p-(1 \rightarrow]$ from the ${ }^{1} \mathrm{H}$ and ${ }^{13} \mathrm{C}$ chemical 
shifts, the small vicinal couplings between $\mathrm{H}-1, \mathrm{H}-2$ and $\mathrm{H}-3$ and the high chemical shifts of the C-3 $\left(\delta_{\mathrm{C}} 76.7 \mathrm{ppm}\right)$ and C-4 $\left(\delta_{\mathrm{C}} 71.7 \mathrm{ppm}\right)$ signals. Residues $\mathbf{H}\left(\delta_{\mathrm{H} 1} / \delta_{\mathrm{C} 1} 4.99 / 101.0 \mathrm{ppm}\right)$ and $\mathbf{I}\left(\delta_{\mathrm{H} 1} / \delta_{\mathrm{C} 1}\right.$ $4.95 / 101.2 \mathrm{ppm})$ were recognized as $\alpha$-Glc $p \mathrm{~A}[\alpha-\mathrm{Glc} p \mathrm{~A}-(1 \rightarrow]$ based on the five-proton spin systems, the large chemical shifts of $\mathrm{H}-4\left(\delta_{\mathrm{H}} 3.39 \mathrm{ppm}\right), \mathrm{H}-5\left(\delta_{\mathrm{H}} 4.03 \mathrm{ppm}\right)$, and C-5 $\left(\delta_{\mathrm{C}} 176.6 \mathrm{ppm}\right)$ signals for residue $\mathbf{H}$ and the chemical shifts of $\mathrm{H}-4\left(\delta_{\mathrm{H}} 3.38 \mathrm{ppm}\right), \mathrm{H}-5\left(\delta_{\mathrm{H}} 4.01 \mathrm{ppm}\right)$, and C-5 $\left(\delta_{\mathrm{C}} 176.7 \mathrm{ppm}\right)$ for residue $\mathbf{I}$ as well as large couplings among $\mathrm{H}-2, \mathrm{H}-3, \mathrm{H}-4$, and $\mathrm{H}-5$. Residue $\mathbf{J}\left(\delta_{\mathrm{H} 1} / \delta_{\mathrm{C} 1} 4.39 / 101.4\right)$ was assigned as the 4,6-disubstituted- $\beta$-Glc $p[\rightarrow 4,6-\beta$-Glc $p \mathrm{~N}-(1 \rightarrow]$ based on the large couplings among all protons in the spin system and the relatively high value of the chemical shift of the $C-4\left(\delta_{C} 79.0 \mathrm{ppm}\right)$ and C-6 $\left(\delta_{\mathrm{C}} 67.3 \mathrm{ppm}\right)$ carbon signals.

Table 3. ${ }^{1} \mathrm{H}$ and ${ }^{13} \mathrm{C}$ NMR chemical shifts of the B. holmesii ATCC 51541 core oligosaccharide ${ }^{\text {a }}$.

\begin{tabular}{|c|c|c|c|c|c|c|c|c|}
\hline \multirow{3}{*}{ Residue } & \multicolumn{8}{|c|}{ Chemical Shifts (ppm) } \\
\hline & H-1 & H-2 & H-3 & $\mathrm{H}-4$ & H-5 & H-6, H-6 & H-7 & H-8, H-8' \\
\hline & C-1 & $\mathrm{C}-2$ & $C-3$ & $\mathrm{C}-4$ & $\mathrm{C}-5$ & C-6 & $\mathrm{C}-7$ & $C-8$ \\
\hline \multirow{2}{*}{ Kdo 4,7-anhKdof } & & & 3.12 & 4.39 & 4.02 & 4.14 & 3.89 & $3.66,3.60$ \\
\hline & & 202.9 & 42.8 & 77.4 & 83.8 & 75.4 & 83.7 & 61.1 \\
\hline \multirow{2}{*}{ Kdo' 4,7-anhKdof } & & & 3.09 & 4.51 & 4.12 & 4.08 & 3.74 & $3.67,3.58$ \\
\hline & & 203.2 & 38.8 & 75.8 & 80.2 & 74.7 & 84.8 & 61.8 \\
\hline \multirow{2}{*}{ A $4-\alpha-$ Glc $p N$} & 5.48 & 3.33 & 3.94 & 3.63 & 3.74 & $3.78,3.73$ & & \\
\hline & 97.3 & 54.5 & 70.3 & 74.9 & 71.9 & 60.5 & & \\
\hline \multirow{2}{*}{ B 2,7-L- $\alpha$-D-Неp $p$} & 5.39 & 3.85 & 3.91 & 3.84 & 3.45 & 4.17 & 3.70 & \\
\hline & 99.7 & 79.8 & 70.4 & 66.5 & 72.1 & 67.9 & 70.3 & \\
\hline \multirow{2}{*}{$\mathrm{C}_{\mathrm{L}-\alpha-\mathrm{D}-\mathrm{Hep} p}$} & 5.27 & 3.96 & 3.74 & 3.81 & 3.54 & 3.94 & 3.62 & \\
\hline & 101.2 & 70.1 & 70.5 & 65.9 & 72.5 & 68.5 & 62.7 & \\
\hline \multirow{2}{*}{ D $\alpha$-Gal $p$ NA } & 5.17 & 3.47 & 4.04 & 4.16 & 4.33 & & & \\
\hline & 94.4 & 50.5 & 66.7 & 69.7 & 72.3 & 175.1 & & \\
\hline \multirow{2}{*}{$\mathbf{E} \alpha-\mathrm{Glc} p \mathrm{~N}$} & 5.12 & 3.28 & 3.86 & 3.44 & 3.70 & $3.78,3.72$ & & \\
\hline & 96.0 & 54.1 & 69.8 & 69.4 & 72.2 & 60.2 & & \\
\hline \multirow{2}{*}{ F 3,4-L- $\alpha-$ D-Hep $p$} & 5.07 & 3.90 & 3.84 & 4.23 & 3.53 & 3.93 & $3.67,3.65$ & \\
\hline & 97.8 & 73.3 & 76.7 & 71.7 & 71.4 & 68.9 & 62.7 & \\
\hline \multirow{2}{*}{$\mathbf{H} \alpha$-GlcpA } & 4.99 & 3.52 & 3.68 & 3.39 & 4.03 & & & \\
\hline & 101.0 & 71.9 & 71.6 & 72.3 & 73.8 & 176.6 & & \\
\hline \multirow{2}{*}{$\mathbf{I}^{\mathbf{b}} \alpha-\mathrm{Glcp} \mathrm{A}$} & 4.95 & 3.52 & 3.67 & 3.38 & 4.01 & & & \\
\hline & 101.2 & 72.1 & 71.6 & 72.2 & 73.9 & 176.7 & & \\
\hline \multirow{2}{*}{$\mathbf{J} 4,6-\beta-G l c p$} & 4.40 & 3.27 & 3.55 & 3.44 & 3.66 & $3.76,3.89$ & & \\
\hline & 101.4 & 73.4 & 76.4 & 79.0 & 73.0 & 67.3 & & \\
\hline
\end{tabular}

\footnotetext{
${ }^{\text {a }}$ Spectra were obtained for ${ }^{2} \mathrm{H}_{2} \mathrm{O}$ solutions at $25^{\circ} \mathrm{C}$. Acetone $\left(\delta_{\mathrm{H}} / \delta_{\mathrm{C}} 2.225 / 31.05 \mathrm{ppm}\right)$ was used as internal reference

$\mathrm{b}$ residue $\mathbf{I}$ is a variant of residue $\mathbf{H}$ in a different chemical environment. For comparison see Figure S1 and Table S1 of the supplementary data.
}

As LPS hydrolysis and chromatographic separations were performed in $1.5 \%$ and $0.05 \mathrm{M}$ acetic acid, respectively, therefore in $2 \mathrm{D}{ }^{1} \mathrm{H}$ and ${ }^{13} \mathrm{C}$ HSQC-DEPT spectra two forms of 4,7-anhydro-3-deoxy-D-manno-2-octulofuranosonic acid instead of 2-keto-3-deoxy-D-manno-octulosonic acid (Kdof and Kdof') were observed. At low $\mathrm{pH}, \mathrm{Kdo}$ is unstable and is converted into different forms $[25,26]$. Specifically, it is an indication of the presence of phosphate at the C-4 position of Kdo in the native OS as the observed forms of 4,7-anhydro-3-deoxy-D-manno-2-octulofuranosonic acid are formed in the process of $\beta$-elimination of phosphate from this position [27]. In ${ }^{31} \mathrm{P}$ NMR spectra of the OSVIII fraction phosphates were not detected (data not shown), but the signals of 4,7-anhKdof and 4,7-anhKdof' imply the presence of phosphate groups in native OS. 
The $\mathrm{J}_{\mathrm{C} 1, \mathrm{H} 1}$ coupling values obtained from the non-decoupled HSQC experiment indicated the $\alpha$-pyranosyl configuration of residues A $(175 \mathrm{~Hz}), \mathbf{B}(178 \mathrm{~Hz}), \mathbf{C}(170 \mathrm{~Hz}), \mathbf{D}(171 \mathrm{~Hz}), \mathbf{E}(173 \mathrm{~Hz})$ and $\mathbf{H} / \mathbf{I}(170 \mathrm{~Hz})$ and the $\beta$-pyranosyl configuration for residue $\mathbf{J}(161 \mathrm{~Hz})$. The sequence of sugar residues was confirmed using inter-residue cross-peaks between the transglycosidic protons observed by ${ }^{1} \mathrm{H}$, ${ }^{1} \mathrm{H}$ NOESY experiments, and between the anomeric protons and carbons at the linkage position in HMBC spectra. The complete ${ }^{1} \mathrm{H}$ and ${ }^{13} \mathrm{C}$ chemical shift data for the core oligosaccharides of B. holmesii ATCC 51541 and B. pertussis 606 have been included in the Supplementary Materials.

The results from all NMR experiments indicated that the structure of the core isolated in the main OS VIII fraction of B. holmesii ATCC 51541 was identical to the OS of B. pertussis 606 (Figure 10).

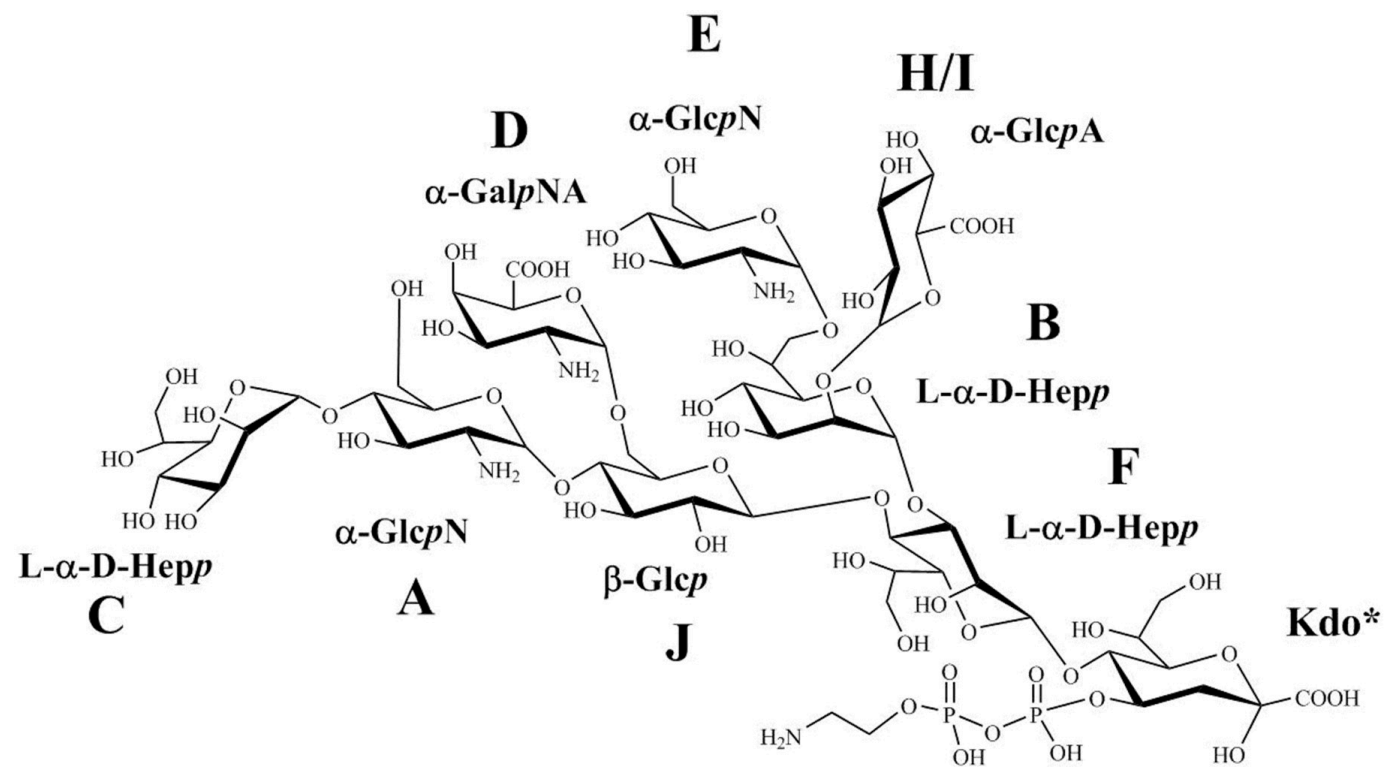

Figure 10. Structure of OS B. holmesii ATCC 51541, * Kdo was detected in the OS VIII fraction in the form of 4,7-anhydro-3-deoxy-D-manno-2-octulofuranosonic acid. The presence of ethanolamine is tentative (for indication see the supplementary data).

\section{Discussion}

We present here the structures of an O-specific polysaccharide, including the structure of the biological repeating unit and a core oligosaccharide of Bordetella holmesii ATCC 51541 lipopolysaccharide in relation to the classical Bordetellae. Current understanding of the whooping-cough etiology has changed, since it is not restricted to infections exclusively caused by $B$. pertussis, but embraces also pertussis-like illnesses caused by B. holmesii and B. parapertussis. B. pertussis is still a primary causative agent of whooping-cough, with $B$. holmesii, emerging as the second, and followed by B. parapertussis $[10,12,13,28]$. The relation between B. pertussis and B. holmesii infections remains unknown, but cases of the co-infection have been reported recently. More importantly, there is no effective vaccine against $B$. holmesii, and the existing pertussis DTwP and DTaP vaccines do not provide cross-protection in animal models of $B$. holmesii infection $[15,29]$. Thus, it is vital to distinguish B. pertussis and B. holmesii infections efficiently as failing to do so may substantially underestimate the efficiency of anti-pertussis vaccination. B. holmesii does not produce the main protein antigens typical for B. pertussis and implicated in the pathogenesis of whooping-cough $[8,15]$. At the moment further studies are required to identify and isolate virulence factors of $B$. holmesii that could become possible antigenic components of new pertussis vaccine compositions and could protect against both B. pertussis and B. holmesii.

One of the common virulence factors and the essential constituent of the bacterial membrane of all Bordetellae is lipopolysaccharide [16]. The lipopolysaccharides (LPS) of Bordetellae differ structurally between species and strains. Lipid A and core oligosaccharide moieties constitute 
the most conservative part of LPS across the genus. The basic structure of O-specific polysaccharides of the B. bronchiseptica and B. parapertussis were defined as homopolymers of the 1,4-linked 2,3-diacetamido-2,3-dideoxy- $\alpha$-galacturonic acid, additionally modified at the non-reducing end terminal sugar by non-carbohydrate residues (e.g., formylation, substitution with aminoacids) [14]. These variable modifications define the antigenic properties of the $\mathrm{O}$-antigens at the strain level. Interestingly, B. pertussis does not express O-antigen. Instead, it can be replaced with a single trisaccharide unit, forming two types of lipooligosaccharides (LOS)—One, built of a dodecasaccharide and another a nonasaccharide linked to lipid A. The polyclonal antibodies directed against the whole bacterial cells of B. pertussis (anti-mixture of B. pertussis strains 186/576/606/629) and these obtained against the neoglycoconjugate of the complete core OS of $B$. pertussis with pertussis toxin reacted with the fast-migrating LPS fractions of $B$. holmesii. No reaction was observed with the slow-migrating LPS fractions of $B$. holmesii cultured on standard Stainer-Scholte medium. Both SDS-PAGE analysis and the observed cross-reactions of the B. holmesii LPS with the polyclonal antibodies directed against the LOS-derived antigens of $B$. pertussis suggested the similarity between the core oligosaccharides of B. holmesii ATCC 51541 and B. pertussis strain 606. Moreover, this observation was in agreement with that reported by Caroff et al. [18]. The results obtained from the comparative analysis of the NMR spectra of B. holmesii core oligosaccharide fraction with this of the B. pertussis strain 606 indicated clearly that the investigated core oligosaccharides were identical. Thus the core OS of B. holmesii conforms to the core nonasaccharide-type that prevails among Bordetellae LPS. The NMR analysis of O-PSI was further supported by mass spectrometry on the partially depolymerized preparations and indicated a unique structure of the pentasaccharide O-repeats, containing one deoxy sugar (Rhap), one galactose (Galp), one glucose (Glcp), and two N-acetylglucosamine (GlcpNAc) residues. Although the isolation of a fraction comprising a single O-repeat linked to the core OS failed, the presence of an un-substituted variant of residue $\mathrm{C}$ at the non-reducing end of the O-PS allowed to define the biological repeating unit. The herein reported O-polysaccharide and core oligosaccharide are the first ones described for the B. holmesii type strain ATCC 51541.

\section{Materials and Methods}

\subsection{Bacteria}

Bordetella holmesii strain ATCC 51541 (DSM 13416) was obtained from DSMZ collection (Leibniz-Institut, Berlin, Germany). B. pertussis strains 186 and 606, used in the current wP vaccine manufactured in Poland, were acquired from the National Medicines Institute (Warsaw, Poland) [30]. Bordetella parapertussis PCM 529 (ATCC 15311), Bordetella bronchiseptica PCM 530 (ATCC 19395), and Bordetella bronchiseptica PCM 1943 (ATCC 4617) came from the PCM collection (Hirszfeld Institute of Immunology and Experimental Therapy, Polish Academy of Sciences, Wrocław, Poland). The strains were stored as bacterial suspensions in PBS containing $20 \%$ glycerol, at $-70{ }^{\circ} \mathrm{C}$. Bacteria were grown on charcoal agar medium supplemented with $10 \%$ defibrinated sheep blood (GRASO Biotech, Owidz, Poland) and then transferred to the liquid medium. B. pertussis strains were cultured using Stainer-Scholte medium at $37{ }^{\circ} \mathrm{C}$ for $72 \mathrm{~h}$ and $\mathrm{B}$. holmesii was cultured in the modified Stainer-Scholte medium with the addition of riboflavin. Bacteria were killed with $1 \%$ phenol, harvested by centrifugation $\left(4000 \times g, 30 \mathrm{~min}, 4^{\circ} \mathrm{C}\right.$ ) (Sorvall Lynx 6000), suspended in water and freeze-dried.

\subsection{Lipopolysaccharides and O-Specific Polysaccharide Fractions}

LPS was extracted from lyophilized bacterial cells by the modified hot phenol/water extraction method [22] and purified by ultracentrifugation [23]. The modified extraction included an extra step prior to the addition of phenol. Briefly, killed and lyophilized bacteria were suspended in $0.05 \mathrm{M}$ phosphate buffer at $\mathrm{pH} 7.4$ and lysozyme (EC 3.2.1.17, specific activity $\geq 40,000 \mathrm{U} / \mathrm{mg}$ ) was added in portions (10 mg per one $\mathrm{g}$ of dry bacterial mass) and the suspension was incubated for $18 \mathrm{~h}$ at $25^{\circ} \mathrm{C}$ with stirring [31]. LPS ( $45 \mathrm{mg}$ ) was hydrolyzed with $1.5 \%$ acetic acid at $100^{\circ} \mathrm{C}$ for $15 \mathrm{~min}$ and subsequently, 
$12 \mathrm{mg}$ of water-soluble heteropolysaccharide was isolated. The supernatant was fractionated using the semi-preparative HPLC UltiMate 3000 chromatographic system (Dionex Corporation, Sunnyvale, CA, USA) on HiLoad 16/600 Superdex 30 prep grade column $(30 \mathrm{~mm} \times 124 \mathrm{~cm}$, grain size $34 \mu \mathrm{m}$, GE Healthcare, Chicago, IL, USA) equilibrated with $0.05 \mathrm{M}$ acetic acid. The chromatography yielded the main fraction containing O-specific polysaccharide (O-PS I, $\sim 1 \mathrm{mg}$ ), separated from shorter O-specific polysaccharide chains (O-PS II, $0.5 \mathrm{mg}$, O-PS III, $0.25 \mathrm{mg}$, O-PS IV, $1 \mathrm{mg}$ ), the core substituted with phosphates (OS V-OS VII, $<0.1 \mathrm{mg}$ ) and main OS fraction containing unsubstituted core oligosaccharides (OS VIII, $2.8 \mathrm{mg}$ ). Eluates were monitored with a Shodex RI-102 detector (Showa-Denko, Tokyo, Japan). All fractions were checked by NMR spectroscopy and matrix-assisted laser desorption/ionization time-of-flight (MALDI-TOF) mass spectrometry (MS).

\subsection{Analytical Procedures}

Monosaccharides were analyzed as their alditol acetates by GC-MS using a Thermo ITQ ${ }^{\mathrm{TM}} 1100$ GC-Ion Trap mass spectrometer coupled with a Trace ${ }^{\mathrm{TM}} 1310$ gas chromatograph (Thermo Scientific ${ }^{\mathrm{TM}}$ ) equipped with HP-5M S column $(30 \mathrm{~m}, \mathrm{ID}=0.25 \mathrm{~mm}, \mathrm{dF}=0.25 \mu \mathrm{m})$ (Agilent Technologies, Lexington, MA, USA) and a temperature gradient $150-270{ }^{\circ} \mathrm{C}$ at $8{ }^{\circ} \mathrm{C} \cdot \mathrm{min}^{-1}$. The absolute configurations of the sugars were determined using ${ }^{1} \mathrm{H}$ NMR spectroscopy by converting the polysaccharide hydrolysate components and relevant monosaccharide standards into O-(S)-2-methyl butyrate derivatives as described by York et al. [24]. For NMR analyzes, the samples were dissolved in acetone-d6 $(\sim 160 \mu \mathrm{L})$ and transferred to $3 \mathrm{~mm}$ diameter NMR tubes.

\subsection{Partial HF Hydrolysis}

The polysaccharide O-PS I fraction $(0.2 \mathrm{mg}, 200 \mu \mathrm{L})$ was hydrolyzed with $48 \%$ hydrofluoric acid at $-20^{\circ} \mathrm{C}$. The O-PS I was dissolved in HF solution portioned and stored at $-20^{\circ} \mathrm{C}$. Everyday a sample $(10 \mu \mathrm{L})$ was taken and the progress of hydrolysis was checked by MALDI-TOF MS. The hydrolysis was ended after 30 days when no polymerized material was detected.

\subsection{SDS-PAGE and Serological Analysis}

The LPS was analyzed by SDS-PAGE according to the method of Laemmli [32]. The LPS bands were visualized by the silver staining method [33] and by immunoblotting using polyclonal rabbit antisera specific for the whole cell of $B$. pertussis (The serum was obtained by immunization with a mixture of $B$. pertussis strains 186/576/606/629) and for the core oligosaccharide of B. pertussis 186 (OS-PT) and the LOS-derived pentasaccharide (penta-PT) in separate experiments. OS-PT and penta-PT conjugates and the corresponding sera were described in the US (US 9878051 B2) patent [34]. All polyclonal rabbit sera were from our Laboratory collection. Immunoblotting was done as previously described [23]. The detection systems consisted of a goat anti-rabbit IgG conjugated with alkaline phosphatase (Bio-Rad, Hercules, CA, USA) as a second antibody and 5-bromo-4-chloro-3-indolyl phosphate-nitroblue tetrazolium.

\subsection{Mass Spectrometry}

MALDI-TOF MS spectra of polysaccharides, oligosaccharides, and lipid A were acquired using UltrafleXtreme (Bruker Daltonik GmbH, Bremen, Germany) with a time-of-flight detector. Spectra were recorded in positive and negative modes. 2,5-Dihydroxybenzoic acid was used as a matrix.

\subsection{NMR Spectroscopy}

NMR spectra of the isolated polysaccharide and oligosaccharides were recorded for ${ }^{2} \mathrm{H}_{2} \mathrm{O}$ solutions at $25^{\circ} \mathrm{C}$ on Bruker Avance III $600 \mathrm{MHz}$ spectrometer (Bruker Biospin GmbH, Rheinstetten, Germany) using $5 \mathrm{~mm}$ QCI cryprobe. $3 \mathrm{~mm}$ tubes $(\sim 160 \mu \mathrm{L})$ were used for the measurements. Polysaccharide and oligosaccharide fractions were repeatedly exchanged with ${ }^{2} \mathrm{H}_{2} \mathrm{O}$ with intermediate lyophilization. 
Acetone $\left(\delta_{\mathrm{H}} / \delta_{\mathrm{C}} 2.225 / 31.05 \mathrm{ppm}\right)$ was used as an internal reference. The data were acquired and processed using TopSpin software (Bruker BioSpin GmbH, Rheinstetten, Germany). The processed spectra were assigned with the help of the NMRFAM-SPARKY program [35]. The signals were assigned by one- and two-dimensional experiments (COSY, TOCSY, NOESY, HMBC, HSQC-DEPT, and HSQC-TOCSY). In the TOCSY experiments, the mixing times used were 30, 60, and $100 \mathrm{~ms}$. The coupling patterns within the identified spin-systems in the 2D TOCSY experiments facilitated the identification of individual monosaccharide residues. The delay time in the HMBC experiment was $60 \mathrm{~ms}$ and the mixing time in the NOESY experiment was $100 \mathrm{~ms}$.

\section{Conclusions}

The relation between B. pertussis and B. holmesii infections remains unknown. To date there is no effective vaccine against $B$. holmesii, and the existing pertussis DTwP and DTaP vaccines do not provide cross-protection in animal models of $B$. holmesii infection [15,29]. Lipopolysaccharide is one of the common virulence factors and the essential constituent of the bacterial membrane of all Bordetellae [16]. In the current research we have elucidated the structures of the O-specific polysaccharide and the core oligosaccharide of B. holmesii ATCC 51541: (1) The B. holmesii O-specific polysaccharide has been identified as the novel pentasaccharide biological repeating unit (Figure 7). (2) The comparative analysis of the NMR spectra of B. holmesii core oligosaccharide fraction with this of the B. pertussis strain 606 indicated their structural identity. These observations were in agreement with SDS-PAGE analysis and the detected cross-reactions of the B. holmesii ATCC 51541 LPS with the polyclonal antibodies directed against the LOS-derived antigens of B. pertussis. Therefore, the core nonasaccharide-type, prevailing among Bordetellae LPS could facilitate a design of a cross-protective neoglycoconjugate as a potential vaccine component.

Supplementary Materials: Supplementary materials can be found at http://www.mdpi.com/1422-0067/21/17/ 6433/s1.

Author Contributions: K.U. cultured bacteria, isolated LPS, and LPS-derived fractions performed and analyzed all the serological experiments and the MALDI-TOF experiments; S.K., K.U., and T.N. performed NMR experiments, K.U. analyzed the data and wrote the original draft of the manuscript. S.K. contributed to data analysis and writings, T.N. provided resources, designed and supervised the experiments; validated the results; reviewed \& edited the paper. All authors have read and agreed to the published version of the manuscript.

Funding: This research received no external funding.

Acknowledgments: This work was supported by the statutory funds of the Laboratory of Microbial Immunochemistry and Vaccines of the Hirszfeld Institute of Immunology \& Experimental Therapy, Polish Academy of Sciences. The costs to publish in open access were covered by the Hirszfeld Institute.

Conflicts of Interest: The authors declare no conflict of interest.

\section{Abbreviations}

$\begin{array}{ll}\text { LPS } & \text { Lipopolysaccharide } \\ \text { O-PS } & \text { O-specific polysaccharide } \\ \text { OS } & \text { Oligosaccharide } \\ \text { NMR } & \text { Nuclear Magnetic Resonance } \\ \text { COSY } & \text { Correlation spectroscopy } \\ \text { TOCSY } & \text { Total correlation spectroscopy } \\ \text { NOESY } & \text { Nuclear Overhauser Effect spectroscopy } \\ \text { HSQC } & \text { Heteronuclear Single Quantum Coherence } \\ \text { DEPT } & \text { Distortionless Enhancement by polarization transfer } \\ \text { HMBC } & \text { Heteronuclear Multiple Bond Correlation } \\ \text { GC } & \text { Gas chromatography } \\ \text { MS } & \text { Mass spectrometry } \\ \text { MALDI-TOF } & \text { Matrix-assisted laser desorption ionization time-of-flight } \\ \text { SDS } & \text { Sodium dodecyl sulfate }\end{array}$




\section{References}

1. Austin, B. The Prokaryotes: Alphaproteobacteria and Betaproteobacteria. In The Family Alcaligenaceae; Rosenberg, E., DeLong, E.F., Lory, S., Stackebrandt, E., Thompson, F., Eds.; Springer International Publishing: Berlin, Germany, 2014; pp. 729-757.

2. Hamidou, S.I.; Linz, B.; Harvill, E.T. Environmental Origin of the Genus Bordetella. Front. Microbiol. 2017, 8, 28. [CrossRef] [PubMed]

3. Weyant, R.S.; Hollis, D.G.; Weaver, R.E.; Amin, M.F.; Steigerwalt, A.G.; O'Connor, S.P.; Whitney, A.M.; Daneshvar, M.I.; Moss, C.W.; Brenner, D.J. Bordetella holmesii Sp. Nov., a New Gram-Negative Species Associated with Septicemia. J. Clin. Microbiol. 1995, 33, 1-7. [CrossRef] [PubMed]

4. Yih, W.K.; Silva, E.A.; Ida, J.; Harrington, N.; Lett, S.M.; George, H. Bordetella holmesii-Like Organisms Isolated from Massachusetts Patients with Pertussis-Like Symptoms. Emerg Infect. Dis. 1999, 5, 441-443. [CrossRef]

5. Weiss, A. Proteobacteria: Alpha and Beta Subclasses. In The Genus Bordetella; Dworkin, M., Falkow, S., Rosenberg, E., Schleifer, K.H., Stackebrandt, E., Eds.; Springer International Publishing: New York, NY, USA, 2006; Volume 5, pp. 648-674. [CrossRef]

6. $\quad$ Linz, B.; Ivanov, Y.V.; Preston, A.; Brinkac, L.; Parkhill, J.; Kim, M.; Harris, S.R.; Goodfield, L.L.; Fry, N.K.; Gorringe, A.R.; et al. Acquisition and Loss of Virulence-Associated Factors During Genome Evolution and Speciation in Three Clades of Bordetella Species. BMC Genom. 2016, 17, 767. [CrossRef] [PubMed]

7. Shepard, C.W.; Daneshvar, M.I.; Kaiser, R.M.; Ashford, D.A.; Lonsway, D.; Patel, J.B.; Morey, R.E.; Jordan, J.G.; Weyant, R.S.; Fischer, M. Bordetella holmesii Bacteremia: A Newly Recognized Clinical Entity among Asplenic Patients. Clin. Infect. Dis. 2004, 38, 799-804. [CrossRef] [PubMed]

8. Diavatopoulos, D.A.; Cummings, C.A.; van der Heide, H.G.J.; Gent, M.V.; Liew, S.; Relman, D.A.; Mooi1, F.R. Characterization of a Highly Conserved Island in the Otherwise Divergent Bordetella holmesii and Bordetella pertussis Genomes. J. Bacteriol. 2006, 188, 8385-8394. [CrossRef]

9. Harvill, E.T.; Goodfield, L.L.; Ivanov, Y.; Smallridge, W.E.; Meyer, J.A.; Cassiday, P.K.; Tondella, M.L.; Brinkac, L.; Sanka, R.; Kim, M.; et al. Genome Sequences of Nine Bordetella holmesii Strains Isolated in the United States. Genome Announc. 2014, 2, 14. [CrossRef]

10. Mir-Cros, A.; Codina, G.; Martín-Gómez, M.T.; Fàbrega, A.; Martínez, X.; Jané, M.; Esso, D.V.; Cornejo, T.; Rodrigo, C.; Campins, M.; et al. Emergence of Bordetella holmesii as a Causative Agent of Whooping Cough, Barcelona, Spain. Emerg Infect. Dis. 2017, 23, 1856-1859. [CrossRef]

11. Guthrie, J.L.; Robertson, A.V.; Tang, P.; Jamieson, F.; Drews, S.J. Novel Duplex Real-Time PCR Assay Detects Bordetella holmesii in Specimens from Patients with Pertussis-Like Symptoms in Ontario, Canada. J. Clin. Microbiol. 2010, 48, 1435-1437. [CrossRef]

12. Rodgers, L.; Martin, S.W.; Cohn, A.; Budd, J.; Marcon, M.; Terranella, A.; Mandal, S.; Salamon, D.; Leber, A.; Tondella, M.L.; et al. Epidemiologic and Laboratory Features of a Large Outbreak of Pertussis-Like Illnesses Associated with Cocirculating Bordetella holmesii and Bordetella pertussis-Ohio, 2010-2011. Clin. Infect. Dis. 2013, 56, 322-331. [CrossRef]

13. Njamkepo, E.; Bonacorsi, S.; Debruyne, M.; Gibaud, S.A.; Guillot, S.; Guiso, N. Significant Finding of Bordetella holmesii DNA in Nasopharyngeal Samples from French Patients with Suspected Pertussis. J. Clin. Microbiol. 2011, 49, 4347-4348. [CrossRef] [PubMed]

14. Preston, A.; Petersen, B.O.; Duus, J.Ø.; Kubler-Kielb, J.; Ben-Menachem, G.; Li, J.J.; Vinogradov, E. Complete Structures of Bordetella bronchiseptica and Bordetella parapertussis Lipopolysaccharides. J. Biol. Chem. 2006, 281, 18135-18144. [CrossRef] [PubMed]

15. Zhang, X.; Weyrich, L.S.; Lavine, J.S.; Karanikas, A.T.; Harvill, E.T. Lack of Cross-protection against Bordetella holmesii after Pertussis Vaccination. Emerg. Infect. Dis. 2012, 18, 1771-1779. [CrossRef] [PubMed]

16. Bouchez, V.; AlBitar-Nehmé, S.; Novikov, A.; Guiso, N.; Caroff, M. Bordetella holmesii: Lipid A Structures and Corresponding Genomic Sequences Comparison in Three Clinical Isolates and the Reference Strain ATCC 51541. Int. J. Mol. Sci. 2017, 18, 1080. [CrossRef]

17. Caroff, M.; Brisson, J.; Martin, A.; Karibian, D. Structure of the Bordetella pertussis 1414 Endotoxin. FEBS Lett. 2000, 477, 8-14. [CrossRef]

18. Caroff, M.; Aussel, L.; Zarrouk, H. Structural Variability and Originality of the Bordetella endotoxins. J. Endotoxin Res. 2001, 7, 63-68. [CrossRef] 
19. Niedziela, T.; Letowska, I.; Lukasiewicz, J.; Kaszowska, M.; Czarnecka, A.; Kenne, L.; Lugowski, C. Epitope of the Vaccine-Type Bordetella pertussis Strain 186 Lipooligosaccharide and Antiendotoxin Activity of Antibodies Directed against the Terminal Pentasaccharide-Tetanus Toxoid Conjugate. Infect. Immun. 2005, 73, 7381-7389. [CrossRef]

20. Vinogradov, E. The Structure of the Carbohydrate Backbone of the Lipopolysaccharides from Bordetella hinzii and Bordetella bronchiseptica. Eur. J. Biochem. 2000, 267, 4577-4582. [CrossRef]

21. Odanaka, K.; Iwatsuki, M.; Satho, T.; Watanabe, M. Identification and Characterization of a Brilliant Yellow Pigment Produced by Bordetella pertussis. Microbiol. Immunol. 2017, 61, 490-496. [CrossRef]

22. Ciucanu, I.; Kerek, F. A Simple and Rapid Method for the Permethylation of Carbohydrates. Carbohydr. Res. 1984, 131, 209-217. [CrossRef]

23. Petersson, C.; Niedziela, T.; Jachymek, W.; Kenne, L.; Zarzecki, P.; Lugowski, C. Structural Studies of the O-Specific Polysaccharide of Hafnia alvei strain PCM 1206 Lipopolysaccharide Containing D-allothreonine. Eur. J. Biochem. 1997, 244, 580-586. [CrossRef] [PubMed]

24. York, W.S.; Hantus, S.; Albersheim, P.; Darvill, A.G. Determination of the Absolute Configuration of Monosaccharides by 1H NMR Spectroscopy of their Per-O-(S)-2-methylbutyrate Derivatives. Carbohydr. Res. 1997, 300, 199-206. [CrossRef]

25. McNicholas, P.A.; Batley, M.; Redmond, J.W. The Reactions of 3-deoxy-d-manno-oct-2-ulosonic Acid (KDO) in Dilute Acid. Carbohydr. Res. 1987, 165, 17-22. [CrossRef]

26. Volk, W.A.; Salomonsky, N.L.; Hunt, D. Xanthomonas Sinensis Cell Wall Lipopolysaccharide. I. Isolation of 4,7-anhydro- and 4,8-anhydro-3-deoxy-octulosonic Acid Following Acid Hydrolysis of Xanthomonas Sinensis Lipopolysaccharide. J. Biol. Chem. 1972, 247, 3881-3887. [PubMed]

27. Clark, H.W.; Mackay, R.M.; Deadman, M.E.; Hood, D.W.; Madsen, J.; Moxon, E.R.; Townsend, J.P.; Reid, K.B.M.; Ahmed, A.; Shaw, A.J. Crystal Structure of a Complex of Surfactant Protein D (SP-D) and Haemophilus influenzae Lipopolysaccharide Reveals Shielding of Core Structures in SP-D-Resistant Strains. Infect. Immun. 2016, 84, 1585-1592. [CrossRef] [PubMed]

28. Valero-Rello, A.; Henares, D.; Acosta, L.; Jane, M.; Jordan, I.; Godoy, P.; Muñoz-Almagro, C. Validation and Implementation of a Diagnostic Algorithm for DNA Detection of Bordetella pertussis, B. parapertussis, and B. holmesii in a Pediatric Referral Hospital in Barcelona, Spain. J. Clin. Microbiol. 2019, 57, 18. [CrossRef] [PubMed]

29. Saito, M.; Odanaka, K.; Otsuka, N.; Kamachi, K.; Watanabe, M. Development of Vaccines Against Pertussis Caused by Bordetella holmesii Using a Mouse Intranasal Challenge Model. Microbiol. Immunol. 2016, 60, 599-608. [CrossRef]

30. Polak, M.; Zasada, A.A.; Mosiej, E.; Krysztopa-Grzybowska, K.; Witkowski, L.; Rzeczkowska, M.; Piekarska, K.; Lutyńska, A. Pertactin-Deficient Bordetella pertussis Isolates in Poland-A Country with Whole-Cell Pertussis Primary Vaccination. Microbes Infect. 2019, 21, 170-175. [CrossRef]

31. Johnson, K.G.; Perry, M.B. Improved Techniques for the Preparation of Bacterial Lipopolysaccharides. Can. J. Microbiol. 1976, 22, 29-34. [CrossRef]

32. Laemmli, U.K. Cleavage of Structural Proteins During the Assembly of the Head of Bacteriophage T4. Nature 1970, 227, 680-685. [CrossRef]

33. Tsai, C.M.; Frasch, C.E. A Sensitive Silver Stain for Detecting Lipopolysaccharides in Polyacrylamide Gels. Anal. Biochem. 1982, 119, 115-119. [CrossRef]

34. Koj, S.; Niedziela, T.; Lugowski, C. Bordetella Pertussis LOS-Derived Oligosaccharide with Pertussis Toxin Glycoconjugate and its Application in the Prophylaxis and Treatment of Infections Caused by Bordetella pertussis. U.S. Patent 9,878,051, 30 Junuary 2018.

35. Lee, W.; Tonelli, M.; Markley, J.L. NMRFAM-SPARKY: Enhanced software for biomolecular NMR spectroscopy. Bioinformatics 2015, 31, 1325-1327. [CrossRef] [PubMed]

(C) 2020 by the authors. Licensee MDPI, Basel, Switzerland. This article is an open access article distributed under the terms and conditions of the Creative Commons Attribution (CC BY) license (http://creativecommons.org/licenses/by/4.0/). 